OPEN ACCESS

Edited by:

Yuli Huang,

Southern Medical University, China

Reviewed by:

Miguel Angel González-Gay,

University of Cantabria, Spain

Hang Xi,

Temple University, United States

*Correspondence:

Yuling Zhang

zhyul@mail.sysu.edu.cn

†These authors have contributed equally to this work

Specialty section

This article was submitted to General Cardiovascular Medicine,

a section of the journal

Frontiers in Cardiovascular Medicine

Received: 07 May 2021

Accepted: 19 July 2021

Published: 10 August 2021

Citation:

Li H, Xu X, Luo B and Zhang Y (2021)

The Predictive Value of Carotid Ultrasonography With Cardiovascular Risk Factors - A "SPIDER" Promoting Atherosclerosis.

Front. Cardiovasc. Med. 8:706490 doi: $10.3389 /$ fcrm.2021.706490

\section{The Predictive Value of Carotid Ultrasonography With Cardiovascular Risk Factors-A "SPIDER" Promoting Atherosclerosis}

\author{
Hongwei $\mathrm{Li}^{1,2+}$, Xiaolin $\mathrm{Xu}^{3+}$, Baoming $\mathrm{Luo}^{3}$ and Yuling Zhang ${ }^{1,2 *}$ \\ ${ }^{1}$ Department of Cardiology, Sun Yat-sen Memorial Hospital, Sun Yat-sen University, Guangzhou, China, ${ }^{2}$ Guangdong \\ Province Key Laboratory of Arrhythmia and Electrophysiology, Guangzhou, China, ${ }^{3}$ Department of Ultrasound, Sun Yat-sen \\ Memorial Hospital, Sun Yat-sen University, Guangzhou, China
}

Insufficient recommendations do not support the clinical use of carotid ultrasonography for further risk stratification in moderate-to-high risk patients with cardiovascular disease (CVD). A literature review was performed to assess six aspects of the research progress and limitations of carotid ultrasonography and carotid atherosclerosis-related risk factors: (1) structures of the carotid intima and media; (2) plaques; (3) inflammation; (4) dynamics of carotid blood flow; (5) early detection and intervention; and (6) risk factors for CVD. Although carotid intima-media thickness and carotid plaques are well-acknowledged independent predictors of CVD risk, normative and cut-off values are difficult to define due to the heterogeneous measurements reported in previous studies. Plaque properties, including location, number, density, and size, become more important risk predictors for cardiovascular disease, but a better approach for clinical use needs to be further established. Three-dimensional ultrasound and contrast-enhanced ultrasound are promising for promoting risk stratification with more details on plaque morphology. Moreover, inflammatory diseases and biomarkers should be evaluated for a full assessment of the inflammatory burden for atherosclerosis. Carotid flow velocity is not only an indicator for stenosis but also a potential risk predictor. Carotid atherosclerosis should be detected and treated early, and additional clinical trials are needed to determine the efficacy of these measures in reducing CVD risk. Cardiovascular risk factors tend to affect carotid plaques, and early treat-to-target therapy might yield clinical benefits. Based on the aforementioned six aspects, we consider that these six important factors act like a "SPIDER" spinning the web of atherosclerosis; a timely comprehensive assessment and intervention may halt the progression to CVD. Carotid ultrasound results should be combined with other atherosclerotic factors, and a comprehensive risk assessment may help to guide cardiovascular prevention decisions.

Keywords: carotid ultrasonography, carotid intima-media thickness, carotid plaque, cardiovascular risk prediction, cardiovascular risk factors

Subject terms: ultrasound, atherosclerosis, vascular disease, cardiovascular disease, peripheral vascular disease. 


\section{BACKGROUND}

Carotid ultrasonography is a non-invasive, non-radioactive and reproducible imaging method used to detect carotid atherosclerosis and screen high-risk patients for cardiovascular disease (CVD). The carotid intima-media thickness (CIMT) is recommended to be measured in asymptomatic patients at intermediate risk for further risk stratification (1). However, the inconsistency in cut-off values and additive values used in cardiovascular risk prediction models limit the clinical application of CIMT $(2,3)$. Although carotid plaques are independently associated with an increased CVD risk and are recommended to be screened in patients with diabetes for a cardiovascular risk evaluation, the current method used to detect the presence of carotid plaques does not comprehensively consider their morphological properties (4-6). Furthermore, evidence that early carotid atherosclerosis interventions are beneficial is lacking (1). Despite the large body of research, no individual parameters of carotid ultrasonography are sufficient for determining an accurate prediction of the cardiovascular risk in asymptomatic patients. Insufficient recommendations limit the clinical use of carotid ultrasonography for cardiovascular risk evaluations as a primary preventative measure. A recent review focusing on the usefulness of carotid ultrasonography for risk stratification of cerebral and cardiovascular disease suggests the need to consider various aspects of carotid ultrasound imaging (7). In addition to carotid ultrasonography itself, there are other atherosclerotic factors affecting carotid atherosclerosis and cardiovascular events. Hence, we further propose a combination of carotid ultrasound, clinical condition, and laboratory tests to comprehensively evaluate the future risk of CVD.

In this review, we summarize the research progress, predictive value and limitations of carotid ultrasonography in determining the structure of the carotid intima and media, plaques and carotid flow velocity, and discuss other carotid atherosclerotic factors, including inflammation, early detection and intervention, and traditional CVD risk factors. A comprehensive cardiovascular assessment based on carotid ultrasonography with other atherosclerotic factors is important for risk stratification and medical decisions.

\section{DIRECT PARAMETERS OF CAROTID ULTRASONOGRAPHY}

\section{Structures of the Carotid Intima and Media CIMT}

An abnormal increase in CIMT reflects the progression of carotid atherosclerosis, which is detected clearly by ultrasound. The CIMT has been suggested to be an independent predictor of the risk of incident CVD in most studies (8-10). Moreover, a slower CIMT progression caused by therapeutic intervention could predict the degree of CVD risk prediction (11). It is measured between the lumen-intima and the media-adventitia interfaces at the far wall of carotid arteries on ultrasound images, which show an obvious "double-line" sign. Changes in the intima and media have been further specified, as the intima layer is thicker and the media layer is thinner in patients with CVD than in healthy subjects (12). There were relatively few small-scale cross-sectional studies calculating the age-specific normal value of CIMT in healthy individuals, but the measurement methods and normative value of CIMT were not identical $(13,14)$. To date, a stable normative value for CVD risk prediction has not yet been defined (2).

The CIMT measurements, endpoint events and cut-off values for the CIMT used in large population-based prospective studies are summarized in Table 1. The discrepancies between studies concern five aspects: (1) the sites of CIMT measurement; (2) the CIMT parameters used for statistical analysis; (3) the endpoints of each study; (4) whether carotid plaques are included; and (5) the cut-off values used for predicting CVD risk.

Most studies measured the CIMT at the far wall of bilateral common carotid arteries (CCAs), but some studies measured the CIMT at both the near and far walls, at the carotid bifurcations (BIFs) and internal carotid arteries (ICAs), or only at the right CCA; measurements were recorded at three different angles or were repeated three times. The maximal CCA-IMT (18); the mean maximal CIMT (5, 9, 15, 20, 24, 26); the mean CIMT normalized by the IMT of the bilateral CCAs, BIFs, and ICAs (8); and the mean CCA-IMT and ICA-IMT of the bilateral carotid arteries $(10,17,22,25,26)$ have been separately used for establishing distinct risk prediction models. For example, Chambless et al. (8) defined the mean CIMT as the average of the bilateral CCA-IMT, BIF-IMT, and ICA-IMT, while Baldassarre et al. (25) and O'Leary et al. (9) reported different values for the mean CIMT of the bilateral CCAs and ICAs.

Growing evidence suggests that CIMT can predict CVD risk partly because of the inclusion of plaques (22), which might magnify the measurement of the IMT and elicit false positive associations with CVD risk. Studies have reported the mean CCA-IMT, excluding plaques, but did not identify an association between the CCA-IMT and risk of incident $\operatorname{CVD}(22,26,29)$. Another source of heterogeneity was the arbitrary cut-off value used to predict the risk of the cardiovascular endpoints. For instance, the top quintile of the mean CCA-IMT was $1.18 \mathrm{~mm}$ in the Cardiovascular Health Study (9), while the top quintile of the mean CCA-IMT was $0.805 \mathrm{~mm}$ in the three-city study (22). Such heterogeneity might affect the comparison and synthesis of CIMT results.

The consensus for the use of carotid ultrasound to evaluate CVD risk and identify subclinical vascular disease issued by the American Society of Echocardiography (ASE) in 2008 established a standard method for CIMT assessment. It is categorized into four parts: (1) a cross-sectional scan for an overview of the arterial wall structure; (2) a Doppler ultrasound scan for identifying significant stenosis; (3) three-angle scans (anterior, lateral, and posterior) for the identification and description of plaques at the near and far walls of bilateral CCAs, bulbs, and ICAs; and (4) three-angle images of the "double line" sign for CIMT measurements, with the distal $1 \mathrm{~cm}$ of each CCA gated 
TABLE 1 | Prospective studies with a large general population that assessed the association between carotid intima-media thickness (CIMT) and cardiovascular risk.

\begin{tabular}{|c|c|c|c|c|c|c|c|}
\hline Study & Year & $\begin{array}{l}\text { Sample } \\
\text { size }\end{array}$ & Age (years) & Follow-up & Measurements & Primary endpoints & Hazard ratio* $(95 \% \mathrm{Cl})$ \\
\hline $\mathrm{KIHD}(5)$ & 1991 & 1,288 & $42-60$ & 1 month -2.5 years & $\begin{array}{l}\text { Mean of the maximal CCA-IMT, far wall, } \\
\text { bilateral, three repeated measures, } \\
\text { mineralized plaque not included }\end{array}$ & AMI & $2.17(1.08-4.26)$ per $0.1 \mathrm{~mm}$ \\
\hline ARIC (8) & 1997 & 12,841 & $45-64$ & Median 5.2 years & $\begin{array}{l}\text { Mean CIMT of CCA + BIF + ICA, far wall, } \\
\text { bilateral }\end{array}$ & $\mathrm{Ml}, \mathrm{CHD}$ death & $\begin{array}{l}\text { IMT } \geq 1 \mathrm{~mm} \text { : women: } 5.07 \text { (3.08-8.36), men: } 1.85 \\
\text { (1.28-2.69); } \\
\text { The third tertile vs. the first tertile: women: } 6.69 \\
(3.01-14.89) \text {, men: } 2.88 \text { (1.91-4.34) }\end{array}$ \\
\hline CHS (9) & 1999 & 4,476 & $72.5 \pm 5.5$ & Median 6.2 years & $\begin{array}{l}\text { Mean of the maximal CCAICA-IMT and } \\
\text { the average CIMT, near and far walls, } \\
\text { bilateral, three repeated measures for ICA, } \\
\text { focal plaque included }\end{array}$ & Ml, stroke & $\begin{array}{l}\text { Relative risk per } 1 \text { SD increase: CCA-IMT: } 1.27 \\
\text { (1.17-1.38); ICA-IMT: } 1.30 \text { (1.20-1.41); average IMT: } \\
\text { 1.36 (1.25-1.47); } \\
\text { The top quintile vs. the bottom quintile: CCA-IMT: } 2.22 \\
\text { (1.58-3.13); ICA-IMT: } 2.47 \text { (1.59-3.85); average IMT: } \\
3.15 \text { (2.19-4.52) }\end{array}$ \\
\hline $\begin{array}{l}\text { Rotterdam study } \\
\text { (15) }\end{array}$ & 2004 & 6,389 & $69.3 \pm 9.2$ & $7-10$ years & $\begin{array}{l}\text { Mean of the maximal CCA-IMT, near and } \\
\text { far walls, bilateral }\end{array}$ & $\mathrm{Ml}$ & $\mathrm{IMT} \geq 1.12 \mathrm{~mm}: 1.95$ (1.19-3.19) \\
\hline MDCS (16) & 2005 & 5,163 & $45-64$ & Median 7 years & CCA-IMT, far wall, right & $\mathrm{Ml}, \mathrm{IHD}$ & $\begin{array}{l}\text { IMT per } 1 \text { SD increase: } 1.23 \text { (1.07-1.41); } \\
\text { The top quintile vs. the bottom quintile: } 2.76(1.05-7.25)\end{array}$ \\
\hline CAPS (17) & 2006 & 5,056 & $50.1 \pm 13.1$ & Mean 4.2 years & Mean CCA/BIF/ICA-IMT, far wall, bilateral & MI, stroke, death & $\begin{array}{l}\text { IMT per } 1 \text { SD increase: CCA: } 1.17(1.08-1.26) \text {; BIF: } 1.14 \\
\text { (1.05-1.24); ICA: } 1.09 \text { (1.01-1.18); } \\
\text { The top quartile vs. the bottom quartile: CCA: } 1.85 \\
(1.09-1.35) \text {; BIF: } 1.27 \text { (0.80-1.99); ICA: } 1.25 \text { (0.84-1.86) }\end{array}$ \\
\hline EAS (18) & 2007 & 1,007 & $69.4 \pm 5.6$ & 12 years & Maximal CCA -IMT, far wall, bilateral & Ml, angina, stroke, IC & $\begin{array}{l}\text { Odd ratios for Ml/stoke with IMT } \geq 0.9 \text { mm: } 1.59 \\
(1.07-2.37)\end{array}$ \\
\hline $\begin{array}{l}\text { Tromsø study } \\
\text { (19) }\end{array}$ & 2007 & 6,226 & $55-74$ & Mean 5.4 years & $\begin{array}{l}\text { Mean CCA-IMT and mean IMT, near and } \\
\text { far walls for the CCA and far walls for the } \\
\text { carotid bulb, right, plaque included }\end{array}$ & $\mathrm{Ml}$ & $\begin{array}{l}\text { Relative risk: the top quartile vs. the bottom quartile: } 1.73 \\
(0.98-3.06) \text { for men and } 2.86(1.07-7.65) \text { for women }\end{array}$ \\
\hline $\operatorname{cccC}(20)$ & 2008 & 2,190 & $\geq 35$ & Median 10.5 years & $\begin{array}{l}\text { Mean of the maximal CCA-IMT, far wall, } \\
\text { bilateral }\end{array}$ & $\begin{array}{l}\text { MI, CHD death, } \\
\text { revascularization }\end{array}$ & $\begin{array}{l}\text { Relative risk for CHD: IMT per } 1 \text { SD increase: } 1.38 \\
(1.12-1.70)\end{array}$ \\
\hline $\begin{array}{l}\text { Cournot et al. } \\
(21)\end{array}$ & 2009 & 2,561 & $51.6 \pm 10.5$ & Median 6 years & $\begin{array}{l}\text { Mean CCA-IMT, far wall, bilateral, } 3 \text { times, } \\
\text { plaque not included }\end{array}$ & $\begin{array}{l}\text { AMl, angina, cardiac } \\
\text { death, sudden death }\end{array}$ & IMT > 0.63: 2.26 (1.35-3.79) \\
\hline $\begin{array}{l}\text { Three-city study } \\
\text { (22) }\end{array}$ & 2011 & 5,895 & $73.3 \pm 4.9$ & Median 5.4 years & $\begin{array}{l}\text { Mean CCA-IMT, far wall, bilateral, plaque } \\
\text { not included }\end{array}$ & $\begin{array}{l}\mathrm{Ml} \text {, angina, } \mathrm{CHD} \text { death, } \\
\text { revascularization }\end{array}$ & $\begin{array}{l}\text { IMT per } 1 \text { SD increase: } 0.8-1.1 \text {; } \\
\text { The top quintile vs. the bottom quintile: } 0.8(0.5-1.2)\end{array}$ \\
\hline $\begin{array}{l}\text { Framingham } \\
\text { offspring study } \\
\text { (23) }\end{array}$ & 2011 & 2,965 & $58 \pm 10$ & Average 7.2 years & $\begin{array}{l}\text { Mean CCA-IMT and maximal ICA-IMT, far } \\
\text { wall, bilateral, end-diastole, plaque not } \\
\text { included }\end{array}$ & $\begin{array}{l}\mathrm{Ml} \text {, angina, } \mathrm{HF}, \mathrm{CHD} \\
\text { death, stroke, IC }\end{array}$ & $\begin{array}{l}\text { IMT per } 1 \text { SD increase: CCA: } 1.13 \text { (1.02-1.24); ICA: } 1.21 \\
(1.13-1.29) \text {; IMT per } 1 \mathrm{~mm} \text { increase: CCA: } 2.46 \\
(1.18-5.13) \text { ICA: } 1.26 \text { (1.16-1.36) }\end{array}$ \\
\hline FATE (24) & 2011 & 1,574 & $49.4 \pm 9.9$ & Mean 7.2 years & $\begin{array}{l}\text { Mean of the maximum CCA-IMT, far wall, } \\
\text { right, at least } 3 \text { repeated measures }\end{array}$ & $\begin{array}{l}\text { MI, RSCA, } \\
\text { revascularization, SVD }\end{array}$ & IMT per 1 SD increase: $1.45(1.15-1.83)$ \\
\hline IMPROVE (25) & 2012 & 3,703 & Mean 64.2 & Median 36.2 months & $\begin{array}{l}\text { Mean and maximal CCA/BIF/ICA-IMT, far } \\
\text { wall, bilateral, } 3 \text { angles, plaque included }\end{array}$ & $\begin{array}{l}\mathrm{Ml} \text {, angina, } \mathrm{HF}, \mathrm{SCD} \text {, } \\
\text { stroke, IC, } \\
\text { revascularization }\end{array}$ & $\begin{array}{l}\text { Mean IMT per 1SD increase: CCA: 1.31 (1.14-1.49); BIF: } \\
\text { 1.24 (1.08-1.44); ICA: } 1.27(1.11-1.44) ; \\
\text { Maximal IMT per 1SD increase: CCA: 1.27 (1.12-1.44); } \\
\text { BIF 1.26 (1.08-1.46); ICA: } 1.30 \text { (1.14-1.50) }\end{array}$ \\
\hline MESA (26) & 2012 & 1,330 & $63.8 \pm 9.5$ & Median 7.6 years & $\begin{array}{l}\text { Mean of the maximal CCA-IMT, far wall, } \\
\text { right, plaque excluded }\end{array}$ & $\begin{array}{l}\mathrm{Ml} \text {, angina, CHD death, } \\
\text { RSCA, revascularization }\end{array}$ & IMT per 1 SD increase: $1.17(0.95-1.45)$ \\
\hline
\end{tabular}



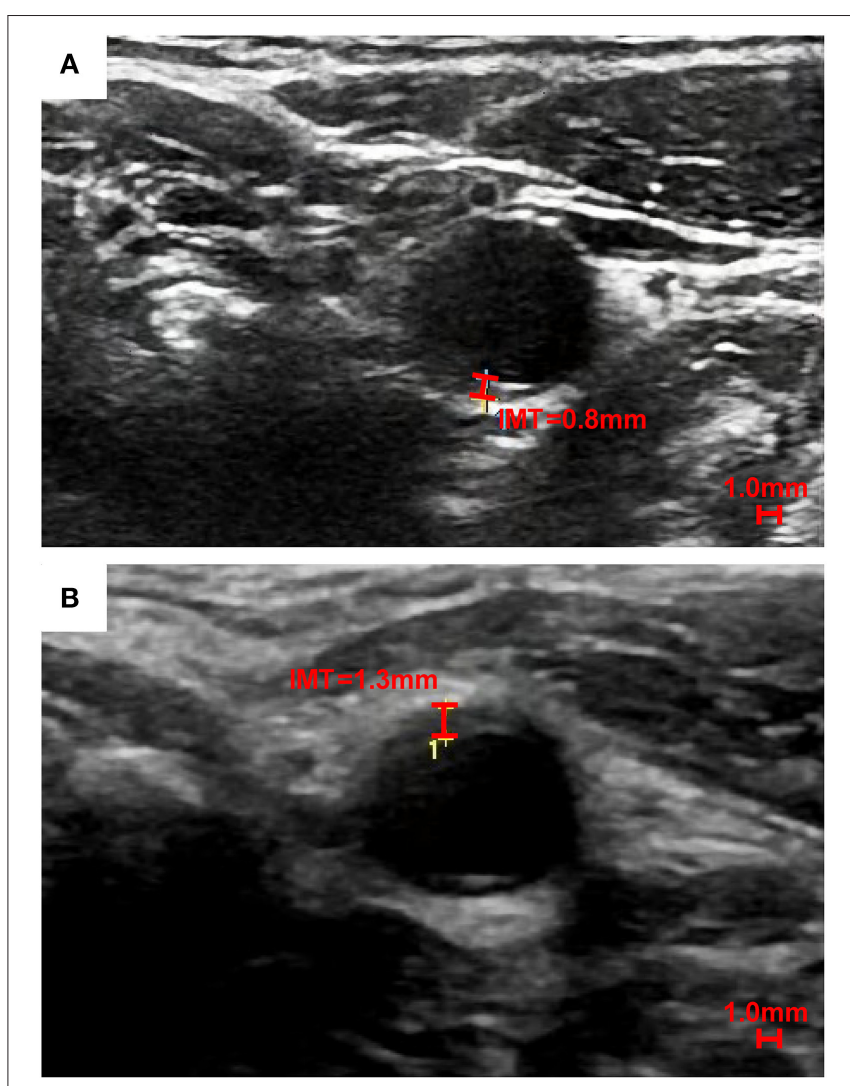

FIGURE 1 | A single-angle cross-sectional scan of the near wall and far wall CIMT of the left CCA. To better show the distinction between the near wall and far wall of common carotid artery, we choose the cross section. The far wall CIMT of a 50 -year-old Chinese man is $0.8 \mathrm{~mm}$ in (A), while the near wall CIMT of a 41 -year-old Chinese man is thicker $(1.3 \mathrm{~mm})$ than the far wall CIMT in (B).

by the optimized R-wave (4). The accuracy of far-wall CCA-IMT measurements has been validated by the absence of a significant difference from in vitro specimens (30), while the near-wall measurements are less accurate due to liable artifacts. Threeangle scans of the CCAs help prevent an irregular CIMT from being inadequately evaluated without considering the near-wall CIMT. For instance, the far-wall CIMT of a 50-year-old man is clearly measured to be 0.8 millimeters $(\mathrm{mm})$ in Figure 1A, while the CIMT of another 41-year-old man was significantly thicker, measuring $1.3 \mathrm{~mm}$ at the near wall in Figure 1B. In addition to CCA-IMT, significantly thicker CIMT values at carotid bulbs and ICAs should not be neglected, especially in patients with normal CCA-IMT values, to avoid underestimations of cardiovascular risk. The Mannheim CIMT and Plaque Consensus states that CIMT can be assessed at carotid bulbs and ICAs (31). A CIMT $\geq 75$ th percentile after adjusting for the patient's age, ethnicity, and sex is recommended as an indication of an increased CVD risk.

A comprehensive meta-analysis of 16 prospective studies performed by the PROG-IMT collaboration revealed a positive association between the mean CCA-CIMT and a 16\% increase in cardiovascular risk but no association between CIMT 
progression and cardiovascular events (32); moreover, the identification of meaningful normative values is difficult due to the substantial heterogeneity in the percentiles of CIMT reported across studies (2). In addition, another meta-analysis challenged the additive value of CIMT, as it showed only a $0.8 \%$ net reclassification improvement (NRI) after it was added to the 10year Framingham risk score (FRS)-based risk prediction model (3). The challenge to the predictive value of CIMT progression and the additive value of CIMT to the FRS reduce the priority to measure the CIMT in cardiovascular risk assessments $(33,34)$. Interestingly, recent research using two cohorts with 20,862 participants from the ARIC study and the CHS study revealed a significantly positive association between CIMT and sudden cardiac death (SCD) during at least 13.1 years of follow-up (27). The long-term predictive value of CIMT for SCD may be better than the unsatisfactory predictive ability of 10-year total cardiovascular risk.

In short, far-wall CIMT is a useful independent predictor for CVD risk, with good reproducibility and accuracy. Due to the heterogeneity of CIMT measurements, CIMT results must be combined with other atherosclerotic markers instead of using carotid ultrasound alone $(18,35)$. Furthermore, the lifetime predictive value of the CIMT in young adults is worth exploring, regardless of whether the 10-year risk predictive value is low.

\section{Carotid Artery Diameters}

The CCA diameter, which is affected by the CIMT and carotid plaques, increases in individuals with carotid atherosclerosis and is measured transversely at a plaque-free site (36). An increased carotid lumen diameter was demonstrated to be associated with increased all-cause mortality (37), but its correlation with incident cardiovascular disease was uncertain. The interadventitia CCA diameter (ICCAD) is easier to detect than the lumen diameter, and an increase in the ICCAD exhibits additive predictive value for composite cardiovascular events (25). A meta-analysis of four cohort studies also reported that patients with a CCA diameter $>8 \mathrm{~mm}$ had a higher risk of total CVD than patients with a diameter $<7 \mathrm{~mm}$ (38). However, direct evidence that the ICCAD or the CCA diameter predicts the risk of coronary heart disease is unavailable (38). Carotid artery diameters represent the structural and functional changes induced by atherosclerosis and may be associated with an increased cardiovascular risk. Carotid arterial diameters should not be neglected in risk assessments.

\section{Plaques}

\section{The Presence of Carotid Plaques}

In people aged 30-79 years, the global prevalence of an increased CIMT is estimated to be $27.6 \%$ and the global prevalence of the presence of carotid plaques is estimated to be $21.1 \%$ in 2020. The percent increase in both an increased CIMT and the presence of carotid plaques is $>50 \%$ in 2020 (39). The carotid atherosclerotic burden is significantly increased worldwide. Accumulating evidence from prospective studies has identified the presence of carotid plaques as a strong independent CVD risk factor, with significant additive value for risk prediction models $(10,40)$. Carotid plaques are defined as having a focal thickness that is at least $50 \%$ greater than that of the surrounding wall or a focal thickness distinct from the adjacent boundary greater than $1.5 \mathrm{~mm}$, with protrusion into the lumen, which easily occurs at carotid bulbs. Carotid plaques are classified into three grades according to the up-to-date recommendations for the assessment of carotid arterial plaque by ultrasound from ASE: grade I is defined as protuberant plaques with CIMT $<1.5 \mathrm{~mm}$, grade II as either protuberant or diffuse plaques with CIMT $\geq 1.5 \mathrm{~mm}$ but $<2.5 \mathrm{~mm}$, and grade III as either protuberant or diffuse plaques with CIMT $\geq 2.5 \mathrm{~mm}$ (41). Plaques are recommended to be detected at both the near and far walls of bilateral CCA, carotid bulb and ICA segments, and the presence of carotid plaques after adjustment for the patient's age, sex, and ethnicity implicates an increased CVD risk $(4,42)$. Carotid atherosclerosis including carotid plaques is a strong cardiovascular predictor, even among patients with previous myocardial infarction or previous stroke (43).

A summary of the large prospective studies on the association between carotid plaques and CVD risk is shown in Table 2. Heterogeneity in plaque measurements mainly exists due to heterogeneity in three aspects: (1) the site at which plaques are detected; (2) the parameters of interest for plaques; and (3) the definition of plaques. Most of the studies detected plaques at bilateral CCAs, carotid bulbs, and ICAs (15). A few studies detected carotid plaques in the bilateral CCAs and bulbs (5), bilateral CCAs and ICAs $(19,21)$, and only the right carotid arteries (16).

The parameters of interest for carotid plaques also varied across studies. Despite the presence of plaques, most studies chose plaque scores to predict the risk $(16,18,20,36)$, while some studies collected data on plaque echogenicity, plaque texture, plaque surface, and plaque area $(9,19,29)$. In addition, early studies defined plaques as a focal area with protrusion into the lumen without a cut-off standard for CIMT, which might lead to overestimations of the predictive value of CIMT. The heterogeneity of plaque parameters also increased the difficulty of identifying a stable cut-off value for plaque number or properties to predict the cardiovascular risk. Uniform quantification of carotid plaques may help to better establish the cut-off value for parameters of carotid plaques in cardiovascular risk prediction.

\section{Plaque Scores}

Various scoring systems with satisfactory predictive ability have been developed to quantitatively measure carotid plaques (Table 3). In the Rotterdam study, the plaque score was computed as the total number of sites where plaques occurred in bilateral CCAs, BIFs, and ICAs, with a total score of 6 points (15). A similar score was calculated for the near and far walls of the bilateral CCAs, BIFs, and ICAs, with a total score of 12 points, in the MESA study (46). Plaque scores reflecting the severity of plaques in carotid arteries also showed a significant association with cardiovascular events $(16,20)$. Handa et al. (48) reported an algorithm that calculated the sum of the bilateral maximal thickness of each plaque in four segments, which was associated with the severity of coronary artery lesions (50). Prati et al. (49) established a scoring system consisting of four parts: the degree of stenosis, echogenicity, heterogeneity of the texture, 


\begin{tabular}{|c|c|c|c|c|c|c|c|}
\hline Study & Year & $\begin{array}{l}\text { Sample } \\
\text { size }\end{array}$ & Age (years) & Follow-up & Measurements & Primary endpoints & Hazard ratio* \\
\hline $\mathrm{KIHD}(5)$ & 1991 & 1,288 & $42-60$ & 1 month -2.5 years & $\begin{array}{l}\text { Bilateral CCAs + carotid bullbs, the presence of plaques, a } \\
\text { focal area with mineralization or protrusion into the lumen }\end{array}$ & AMl & $\begin{array}{l}\text { Small plaque: } 4.15 \text { (1.15-11.47); } \\
\text { Stenotic plaque }{ }^{\dagger}: 6.71(1.33-33.91)\end{array}$ \\
\hline $\begin{array}{l}\text { Rotterdam study } \\
\text { (15) }\end{array}$ & 2004 & 6,389 & $69.3 \pm 9.2$ & At least 7 years & $\begin{array}{l}\text { Bilateral CCAs }+ \text { carotid bulbs }+ \text { ICAs, the presence of } \\
\text { plaques and plaque score, a focal area with protrusion into } \\
\text { the lumen }\end{array}$ & $\mathrm{Ml}$ & Plaque score $\geq 3$ points: 1.38 (1.27-2.62) \\
\hline MDCS (16) & 2005 & 5,163 & $45-64$ & Median 7 years & $\begin{array}{l}\text { Right CCA + carotid bulb + ICA + ECA, the presence of } \\
\text { plaques and plaque score, a focal thickening of IMT }>1.2 \mathrm{~mm}\end{array}$ & $\mathrm{Ml}, \mathrm{HD}$ & $\begin{array}{l}\text { Plaque score per } 1 \mathrm{SD} \text { increase: } 1.39 \\
(1.10-1.78)\end{array}$ \\
\hline $\mathrm{CHS}(44)$ & 2007 & 5,020 & $72.6 \pm 5.5$ & Median 11 years & $\begin{array}{l}\text { Bilateral CCAs + ICAs, classification of plaques, the largest } \\
\text { focal lesion classified by surface characteristics, echogenicity, } \\
\text { and texture }\end{array}$ & $\begin{array}{l}\text { MI, stroke, cardiovascular } \\
\text { death, all-cause death }\end{array}$ & High-risk plaque ${ }^{\ddagger}$ : 1.38 (1.14-1.67) \\
\hline $\begin{array}{l}\text { Tromsø study } \\
\text { (19) }\end{array}$ & 2007 & 6,226 & $55-74$ & Mean 5.4 years & $\begin{array}{l}\text { Bilateral CCAs + carotid bulbs + ICAs, the presence of } \\
\text { plaques + plaque echogenicity (grade } 1-4 \text { ) + plaque area, a } \\
\text { focal area with protrusion into the lumen }\end{array}$ & $\mathrm{Ml}$ & $\begin{array}{l}\text { Relative risk according to plaque area: the } \\
\text { top tertile vs. no plaque: } 1.56 \text { (1.04-2.36) } \\
\text { for men; } \\
3.95 \text { (2.16-7.19) for women; } \\
\text { Echogenicity: the bottom tertile vs. no } \\
\text { plaque: } 1.08 \text { (0.68-1.70) for men; } \\
2.79 \text { (1.45-5.37) for women }\end{array}$ \\
\hline NOMAS (45) & 2007 & 1,118 & $68 \pm 8$ & Mean 2.7 years & $\begin{array}{l}\text { Bilateral CCAs + ICAs, the presence of plaques and calcified } \\
\text { plaque, a focal area with protrusion } 50 \% \text { greater than the } \\
\text { surrounding wall and plaques with acoustic shadowing were } \\
\text { calcified }\end{array}$ & $\begin{array}{l}\text { Ml, stroke, vascular } \\
\text { death }\end{array}$ & $\begin{array}{l}\text { Calcified plaques vs. no plaque: } 2.4 \\
(1.0-5.8)\end{array}$ \\
\hline NOMAS (6) & 2008 & 2,189 & $68 \pm 10$ & Mean 6.9 years & $\begin{array}{l}\text { Bilateral CCAs + BIFs + ICAs, MCPT, a focal area with } \\
\text { protrusion } 50 \% \text { greater than the surrounding wall }\end{array}$ & $\begin{array}{l}\mathrm{Ml} \text {, stroke, vascular } \\
\text { death }\end{array}$ & $\begin{array}{l}\text { MCPT } \geq 1.9 \mathrm{~mm} \text { vs. no plaque: } 1.48 \\
(1.05-2.10)\end{array}$ \\
\hline $\operatorname{cccc}(20)$ & 2008 & 2,190 & $\geq 35$ & Median 10.5 years & $\begin{array}{l}\text { Bilateral CCAs + carotid bulbs + ICAs + ECAs, the severity } \\
\text { of plaque score }\end{array}$ & $\begin{array}{l}\mathrm{Ml}, \mathrm{CHD} \text { death, } \\
\text { revascularization }\end{array}$ & $\begin{array}{l}\text { Relative risk for CHD: } 1.15(1.07-1.24) \text { per } \\
1 \text { increase in plaque score }\end{array}$ \\
\hline $\begin{array}{l}\text { Cournot et al. } \\
(21)\end{array}$ & 2009 & 2,561 & $51.6 \pm 10.5$ & Median 6 years & $\begin{array}{l}\text { Bilateral CCAs + ICAs, the presence of plaques, a focal area } \\
\text { with hyperechogenicity or protrusion into the lumen }\end{array}$ & $\begin{array}{l}\text { AMl, angina, cardiac } \\
\text { death, sudden death }\end{array}$ & $2.81(1.84-4.29)$ \\
\hline $\begin{array}{l}\text { Three-city study } \\
\text { (22) }\end{array}$ & 2011 & 5,895 & $73.3 \pm 4.9$ & Median 5.4 years & $\begin{array}{l}\text { Bilateral CCAs + BIFs + ICAs, the presence of plaques, a } \\
\text { focal area with protrusion into the lumen for at least } 50 \% \\
\text { greater than the surrounding vessel wall }\end{array}$ & $\begin{array}{l}\mathrm{Ml} \text {, angina, } \mathrm{CHD} \text { death, } \\
\mathrm{PCl} \text {, CABG }\end{array}$ & $\begin{array}{l}\text { Plaques at } \geq 2 \text { sites vs. no plaque: } 2.2 \\
(1.6-3.1)\end{array}$ \\
\hline $\begin{array}{l}\text { Framingham } \\
\text { offspring study } \\
\text { (23) }\end{array}$ & 2011 & 2,965 & $58 \pm 10$ & Average 7.2 years & $\begin{array}{l}\text { Bilateral ICA, the presence of plaques, an area of IMT } \geq \\
1.5 \mathrm{~mm}\end{array}$ & $\begin{array}{l}\mathrm{Ml} \text {, angina, } \mathrm{CHD} \text { death, } \\
\text { stroke, IC, HF }\end{array}$ & $1.92(1.49-2.47)$ \\
\hline MESA (10) & 2013 & 6,562 & $61.1 \pm 10.2$ & Mean 7.8 years & $\begin{array}{l}\text { Bilateral CCAs + BIFs + ICAs, the presence of plaques, a } \\
\text { focal area with protrusion into the lumen }\end{array}$ & $\begin{array}{l}\mathrm{Ml} \text {, angina, } \mathrm{CHD} \text { death, } \\
\mathrm{RSCA}\end{array}$ & $1.45(1.20-1.76)$ \\
\hline $\begin{array}{l}\text { High-risk plaque } \\
\text { Biolmage (29) }\end{array}$ & 2017 & 5,808 & Average 69 & Median 2.7 years & $\begin{array}{l}\text { Bilateral carotid arteries, MCPT and total plaque area }\left(\mathrm{mm}^{2}\right) \text {, } \\
\text { a focal protrusion } \geq 0.5 \mathrm{~mm} \text { or } 50 \% \text { of the surrounding wall; } \\
\text { or IMT }>1.5 \mathrm{~mm}\end{array}$ & $\begin{array}{l}\text { MI, stroke, cardiovascular } \\
\text { death }\end{array}$ & $\begin{array}{l}\text { The top tertile vs. the bottom tertile: } \\
\text { MCPT: } 1.96 \text { (0.91-4.25); } \\
\text { Total plaque area: } 2.36 \text { (1.13-4.92) }\end{array}$ \\
\hline MESA (46) & 2017 & 4,955 & $61.6 \pm 10.1$ & Median 11.3 years & $\begin{array}{l}\text { Bilateral CCAs + BIFs + ICAs, plaque score, a focal } \\
\text { thickness of IMT }>1.5 \mathrm{~mm} \text { or }>50 \% \text { of the surrounding wall }\end{array}$ & $\begin{array}{l}\mathrm{Ml} \text {, angina, } \mathrm{CHD} \text { death, } \\
\mathrm{RSCA} \text {, stroke }\end{array}$ & $\begin{array}{l}\text { Plaque score per } 1 \text { SD increase: } 1.27 \\
(1.16-1.40)\end{array}$ \\
\hline MESA (47) & 2018 & 2,706 & $65.4 \pm 9.6$ & Mean 13.3 years & $\begin{array}{l}\text { Bilateral CCAs + BIFs + ICAs, plaque score and total plaque } \\
\text { score and greyscale plaque features }\end{array}$ & $\begin{array}{l}\mathrm{Ml} \text {, angina, } \mathrm{CHD} \text { death, } \\
\mathrm{RSCA} \text {, stroke }\end{array}$ & $\begin{array}{l}\text { Total plaque area per } 1 \mathrm{SD} \text { increase: } 1.23 \\
(1.11,1.36) ; \text { carotid plaque score per } 1 \mathrm{SD} \\
\text { increase: } 1.33(1.18-1.49)\end{array}$ \\
\hline
\end{tabular}

roke, vascular

MI, stroke, vascular eath ina, $\mathrm{CHD}$ death, $\mathrm{Ml}$, angina, $\mathrm{CHD}$ death, IC, HF

RSCA

angina, $\mathrm{CHD}$ death,

$\mathrm{Ml}$, angina, $\mathrm{CHD}$ death, increase: $1.33(1.18-1.49)$ 


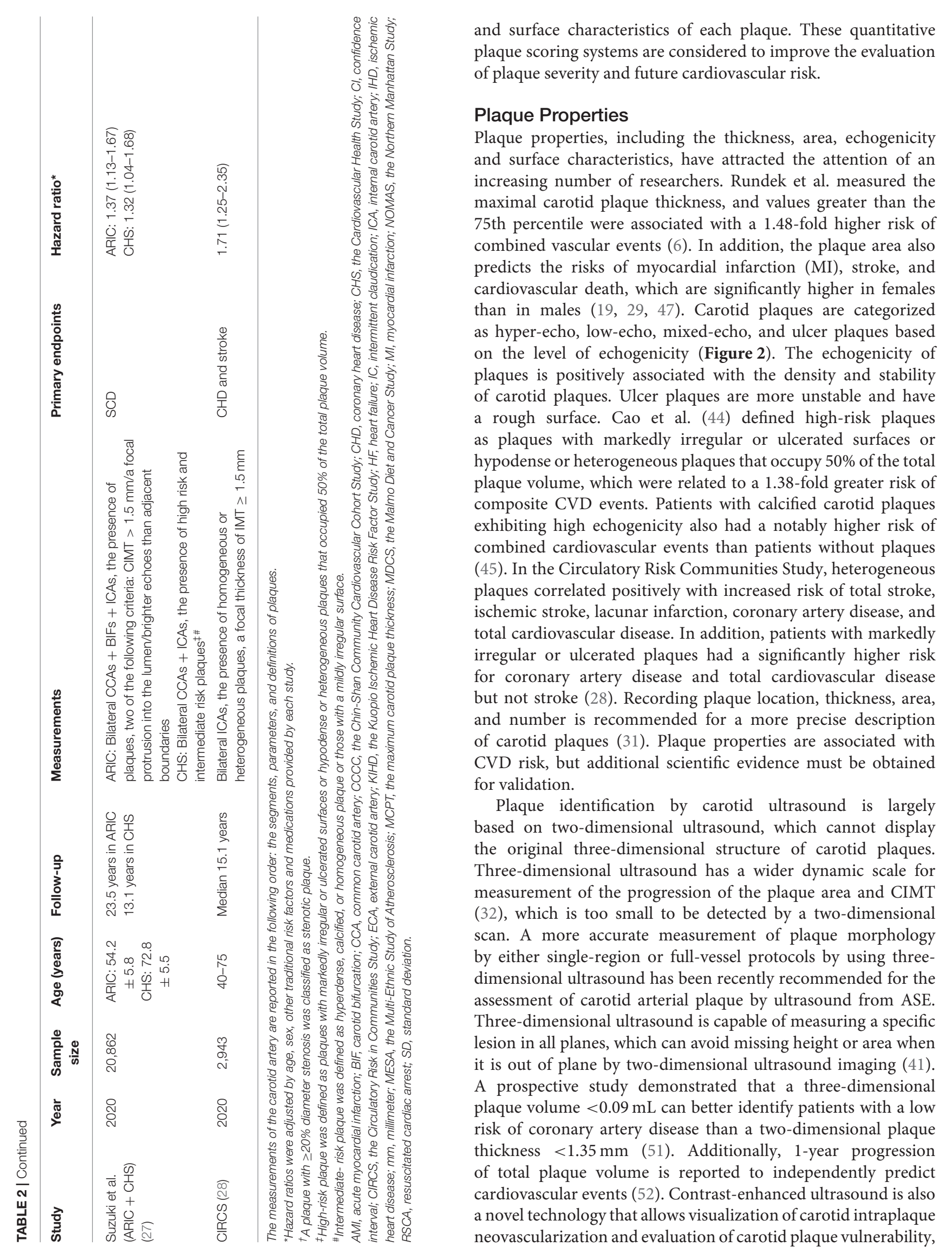


TABLE 3 | Differences between the carotid plaque scoring systems.

\begin{tabular}{|c|c|}
\hline Study & Scoring system \\
\hline $\begin{array}{l}\text { Rotterdam study } \\
\text { (15) and MESA } \\
\text { (46) }\end{array}$ & The sum of the sites with plaque in (the near and far walls of) the CCA, BIF, and ICA \\
\hline MDCS (16) & $\begin{array}{l}\text { A scale dependent on the severity of BIF: } 0=\text { normal; } 1=\text { one small plaque }\left(<10 \mathrm{~mm}^{2}\right) ; 2=\text { small plaques } \geq 2 ; 3=\text { one large plaque }\left(>10 \mathrm{~mm}{ }^{2}\right) ; 4 \\
=\text { one large plaque plus small plaques; } 5=\text { large plaques } \geq 2 \text { or one plaque with stenosis }>50 \% \text { or circumferent }\end{array}$ \\
\hline $\operatorname{CCCC}(20)$ & $\begin{array}{l}\text { The total grade of each CCA, carotid bulb, ICA and ECA bilaterally: grade } 0=\text { normal; } 1=\text { one small plaque (stenosis: }<30 \% \text { ); } 2=\text { one medium plaque } \\
\text { (stenosis: } 30-49 \% \text { ) or multiple small plaques; } 3=\text { one large plaque (stenosis: } 50-99 \% \text { ) or multiple plaques with medium plaque } \geq 1 ; 4=0 c c l u s i o n\end{array}$ \\
\hline Handa et al. (48) & $\begin{array}{l}\text { The sum of the bilateral maximal thickness of each plaque in the area from the ICA }<15 \mathrm{~mm} \text { proximal to the BIF region to the CCA }>30 \text { mm proximal } \\
\text { to the BIF region. }\end{array}$ \\
\hline Prati et al. (49) & $\begin{array}{l}\text { The total score of four parameters: (1) stenosis } \geq 40 \%=1 \text {; (2) echogenicity from low (1) to high (3); (3) heterogeneous texture with complex echo } \\
\text { pattern }=1 \text {; and (4) irregular surface }=1 \text {. In addition, the plaque with the highest score was analyzed. }\end{array}$ \\
\hline
\end{tabular}

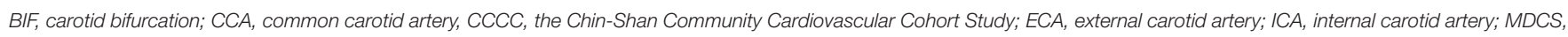
the Malmo Diet and Cancer Study; MESA, the Multi-Ethnic Study of Atherosclerosis; mm, millimeter.

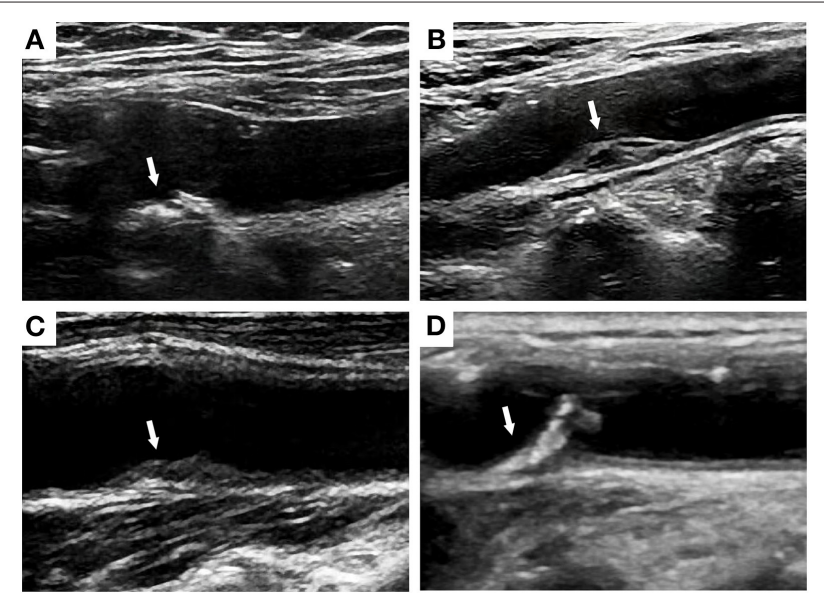

FIGURE 2 | Ultrasound images of hyper-echo (A), low-echo (B), mixed-echo (C), and ulcer plaques (D) at the carotid bulbs.

and an increased carotid intraplaque neovascularization score is a strong predictor for significant coronary artery disease, with high sensitivity and specificity $(53,54)$. Superb microvascular imaging ultrasound without contrast is a novel technology using an algorithm to remove clutter and motion wall artifacts under the condition of low-velocity blood flow, and seems to detect carotid intraplaque neovascularization accurately comparable to contrast-enhanced ultrasound (55). Plaque properties obtained by three-dimensional ultrasound, contrast-enhanced ultrasound, and superb microvascular imaging appear to be powerful tools of cardiovascular risk assessment in clinical use, but further studies are necessary to validate precise and practical parameters.

In summary, carotid plaques are more powerful risk predictors than CIMT and should be reported in combination with CIMT (4). For high-risk patients with diabetes whose stratification of CVD risk may be underestimated by traditional risk assessments, carotid plaques should be measured for risk stratification (34).

\section{Dynamics of Carotid Blood Flow Carotid Flow Velocity}

Carotid flow velocity, specifically peak-systolic velocity (PSV), as measured by gray-scale or Doppler ultrasound, is always used to classify ICA stenosis. For instance, a PSV $\geq 125 \mathrm{~cm} / \mathrm{s}$ indicates ICA stenosis rate $\geq 50 \%$, while a PSV $\geq 230 \mathrm{~cm} / \mathrm{s}$ indicates $>80 \%$ ICA stenosis. When the ICA stenosis rate is $>90 \%$, PSV is undetectable (56). However, the predictive ability of carotid flow velocity remains unclear. A large follow-up study measured end diastolic velocity (EDV), which was reported to be associated with ischemic stroke. Patients with a low EDV and high IMT exhibited a 2.10 -fold higher risk of ischemic stroke than patients with a high EDV and low IMT. However, the predictive value of a low EDV for coronary events has not been validated (57). Another cohort study of patients with hypertension revealed a higher risk of composite cardiovascular events that was related to a PSV/systolic carotid artery diameter $<85.7$ s, which provided additive value for risk prediction models (58). Additional studies should be conducted to confirm the association between carotid flow velocity and the risk of coronary heart disease. Carotid flow velocity should not be merely considered as a stratification standard for diameter stenosis.

\section{Shear Stress of Carotid Artery Wall}

The disrupted and turbulent flow at the stenosis location may promote carotid plaque formation. An asymmetrical distribution of CIMT is closely correlated with hemodynamic changes across the carotid artery, and the highest CIMT was reported to be located at the posteromedial wall of the bifurcation and internal carotid segments and the anterolateral wall of the common carotid segment (59). The maximum wall shear stress appears at the peak of carotid plaques, while the minimum wall shear stress was reported to be located at the place after passing of the peak, which was lower than non-stenotic areas (60). The reduction in carotid endothelial shear stress with age was also an independent predictor of carotid plaque development (61). Goudot et al. suggested that a combination of maximal wall shear stress at the peak of carotid plaque and shear wave elastography texture predicted vulnerable carotid plaques with good performance 
(62). However, there is no reference value of shear stress for vascular evaluation in clinical practice. Additionally, perivascular adipose tissue also participates in carotid plaque formation induced by disturbed flow in $\mathrm{ApoE}^{-/-}$mice which may be mediated by focal inflammation attenuation (63). Haberka and Gasior provided a novel index of the perivascular adipose index, carotid extra-media thickness (EMT), and found that EMT was positively associated with cardiometabolic risk factors (64). Detection of perivascular adipose tissue by the combination of inflammatory markers and imaging for cardiovascular risk prediction requires further struggles.

\section{EARLY DETECTION AND INTERVENTION}

CIMT is recommended to be measured in intermediaterisk adults for additional risk stratification. However, whether the early detection of carotid atherosclerosis is beneficial for improving clinical outcomes remains uncertain. There is no strong evidence that suggests the need for therapies for abnormal CIMT (1). Whether extra measures for the early detection and treatment of carotid atherosclerosis are needed is a key question.

A recent randomized controlled study compared the FRS between patients who were informed of their carotid ultrasound results and patients who did not receive their results, and a significant decrease in the FRS from baseline to the 1-year follow-up was unexpectedly observed in the intervention group. Thus, an awareness of subclinical carotid atherosclerosis is beneficial for reducing cardiovascular risk, which might originate from improved compliance with medication and lifestyle modifications (65). In addition, a treat-to-target approach for CVD risk factors, including lifestyle interventions and medications, contributed to slower CIMT progression and lower morbidity related to cardiovascular events compared to usual care in patients with rheumatoid arthritis who did not present with CVD (66). However, in elderly patients with type 2 diabetes and coronary artery disease, the CIMT of patients without identified carotid plaques was reduced by a 1year exercise training program (67). These studies stressed the importance of early detection and intervention for subclinical carotid atherosclerosis. Carotid ultrasonography may also help to evaluate cerebrovascular and cardiovascular risk without unnecessary invasive examination in low-risk patients with infectious disease, including human immunodeficiency infection and COVID-19 $(68,69)$. Hence, an early alarm and intervention based on carotid ultrasound results might prevent irreversible outcomes of carotid plaques or established CVD.

\section{CARDIOVASCULAR RISK FACTORS RELATED TO CAROTID ATHEROSCLEROSIS}

\section{Inflammation}

Inflammation plays an important role in carotid atherosclerosis. The CIMT and presence of carotid plaques are positively correlated with systematic inflammatory diseases and chronic inflammation $(70,71)$. Patients with chronic inflammatory disease are at increased risk of cardiovascular events. This is the case for rheumatoid arthritis, the prototype of a chronic inflammatory disease, which is associated with accelerated atherosclerosis (72). Interestingly, several studies have revealed that both CIMT (73) and the presence of carotid plaques (74) are strong predictors of future cardiovascular events in patients with rheumatoid arthritis. Furthermore, carotid ultrasound, as well as other surrogate markers, better identifies rheumatoid arthritis patients with a very high risk of cardiovascular disease than welldefined risk chart algorithms, such as the Systematic Coronary Risk Assessment (SCORE) (75, 76). Moreover, inflammatory intermediate monocytes are reported to correlate strongly with CIMT (77). A proteomic analysis also revealed that CIMT mainly correlates with chemotaxis-related proteins rather than other inflammatory proteins (78). According to the Canakinumab Anti-inflammatory Thrombosis Outcome study (CANTOS), the administration of anti-inflammatory therapy reveals a close association between inflammation and cardiovascular disease (79). An increased inflammatory burden should be carefully considered when carotid ultrasound results are interpreted.

\section{Traditional Inflammatory Markers}

High-sensitivity C-reactive protein (hsCRP) and serum amyloid A (SAA) are two of the classic acute-phase proteins that have been proven to be independent cardiovascular risk predictors $(26,35)$. A large asymptomatic cohort revealed a positive association of hsCRP and SAA with the risk for carotid atherosclerotic progression (80). Interestingly, high hsCRP levels predict CVD mortality only in patients with severe atherosclerosis but not in patients with atherosclerosis (44). In addition to hsCRP, other traditional inflammatory markers including fibrinogen and leukocyte counts were demonstrated to be independently associated with the progression of CIMT (81).

\section{Cytokines, Chemokines, and Other Novel Inflammatory Factors}

A recent systematic review provided a summary of high-risk carotid plaque-related inflammatory cytokines (interleukin-6, interleukin-1 $\beta$, tumor necrosis factor- $\alpha$, etc.), chemokines (monocyte chemotactic protein-1, MCP-1), endothelial and cell adhesion factors (intracellular adhesion molecule-1, vascular cell adhesion molecules-1, and selectins), proteolysis factors (matrix metalloproteinases), metabolic biomarkers (lipids, adipokines, homocysteine, etc.), angiogenic markers (vascular endothelial growth factor), and thrombotic biomarkers (plasminogen activator inhibitor-1) (82). Among these serum biomarkers, interleukin 6 was also demonstrated to further increase the predictive capacity, accompanied by the presence of carotid plaques, for obstructive coronary artery disease (83). Other serum inflammatory markers play an important role in both carotid and coronary atherosclerosis. Neopterin, an activation biomarker for monocytes/macrophages, is positively associated with both complex carotid plaques and coronary artery disease $(84,85)$. High lipoprotein-associated phospholipase A2 (LpPLA2), correlated with a high risk of coronary artery disease, is significantly associated with the symptomatic status of carotid plaques $(86,87)$. Fatty acid binding protein 4 , an important 
inflammatory protein also participating in macrophage cholesterol trafficking, is positively correlated with carotid plaques and stroke symptoms and clearly predicts the risk of cardiovascular mortality $(88,89)$. Local inflammation of carotid atherosclerosis can be assessed by 2 -deoxy-2-[ $\left[{ }^{18} \mathrm{~F}\right]$ fluoro-Dglucose positron emission tomography/computed tomography $\left({ }^{18} \mathrm{~F}-\mathrm{FDG} \mathrm{PET} / \mathrm{CT}\right)$ and the expression inflammatory markers at carotid plaque lesions (86). A high level of galectin 3, a novel vascular inflammatory marker, is a strong predictor of heart failure and poor cardiovascular outcome (90). However, a low intraplaque concentration of galectin-3 is associated with symptomatic and unstable carotid plaques, which can be reversed by short-term statin treatment (91). Serum complement complex C5b-C9 was also an independent risk factor for unstable carotid plaques in patients with acute ischemic stroke (92), whereas the relationship between complement C3 and carotid plaques was controversial in patients with systematic lupus erythematosus $(93,94)$. Some activated $\mathrm{T}$ and $\mathrm{B}$ cells, including $\mathrm{CD}_{3}{ }^{+} \mathrm{HLA}^{-D R}{ }^{+} \mathrm{T}$ cells, $\mathrm{CD} 19^{+} \mathrm{CD} 6^{+} \mathrm{B}$ cells, $\mathrm{CD} 20^{+} \mathrm{CD} 69^{+}$ $\mathrm{T}$ cells, and $\mathrm{CD}^{+} 6^{+}$monocytes, were also found to be associated with CIMT, carotid plaques, and the severity of stenosis (95).

Furthermore, moderate doses of statins have been shown to decrease MCP-1 levels followed by CIMT regression, indicating that anti-inflammatory drugs reverse carotid atherosclerosis (96). Therefore, inflammation should be simultaneously assessed with carotid ultrasound for comprehensive evaluations of cardiovascular risk.

\section{Risk Factors for CVD \\ High-Density Lipoprotein}

A low high-density lipoprotein cholesterol (HDL-C) level is wellacknowledged to be associated with high cardiovascular risk, and is also associated with elevated CIMT and carotid plaque burden (97). An elevation in HDL-C levels was shown to be correlated with a reduction in carotid plaque growth in patients with preexisting carotid plaques (98). With the advancement of HDL quality studies, other HDL-related metrics were also found to be associated with carotid atherosclerosis. El Khoudary et al. reported that higher large HDL particles via ion-mobility were associated with higher CIMT close to menopause but with lower CIMT in the postmenopausal period (99). Moreover, HDL2-C was positively associated with carotid plaque thickness, while HDL3-C was inversely associated with carotid plaque area (100). The relationship between protein components in HDL and carotid atherosclerosis was also investigated. Aroner et al. found that HDL containing apoC-III was positively associated with carotid plaque score, while HDL lacking apoC-III was negatively associated with carotid plaque score and CIMT, which supported the role of apoC-III in HDL in carotid atherosclerosis (101). Surprisingly, Shea et al. reported that HDL-mediated cholesterol efflux capacity was positively associated with carotid plaque progression, but negatively associated with incident hard CVD based on cross-sectional analysis (102). The correlation between HDL function and carotid atherosclerosis requires further investigation. Non-HDL-C, calculated as total cholesterol minus $\mathrm{HDL}-\mathrm{C}$, and the non-HDL-C/HDL-C ratio were also cardiovascular risk factors positively associated with carotid atherosclerosis $(103,104)$. In total, HDL-related metrics were important variables for cardiovascular risk prediction and the evaluation of carotid atherosclerosis.

\section{Low-Density Lipoprotein}

Low-density lipoprotein cholesterol (LDL-C) is a strong predictor for both cerebrovascular events and cardiovascular events, and the recommended target of LDL-C becomes lower in order to reduce residual risk (105). A greater possibility of a higher carotid plaque score was demonstrated to be related to an increase in LDL-C within 1 year of the final menstrual period, which might be associated with an elevation of cardiovascular risk for postmenopausal women (106). Furthermore, an increased circulating oxidized LDL-C was significantly associated with a higher risk of 10-year progression of subclinical carotid plaques (107). However, a targeted LDLC level of $<70 \mathrm{mg} / \mathrm{dL}$ did not reduce the incidence of newly diagnosed carotid plaque compared to a higher LDL-C target in patients with ischemic stroke (108). Therefore, early target control of LDL-C before the incidence of atherosclerotic events is more beneficial in cardiovascular prevention.

\section{Diabetes}

Diabetes is one of the strongest risk factors for both carotid atherosclerosis and CVD, and the detection of carotid plaque is recommended in diabetic high-risk patients $(39,109)$. The presence of echogenic carotid plaques, compared to that of echolucent and heterogeneous plaques, was demonstrated to be a stronger predictor for incident major adverse cardiovascular events in patients with type 2 diabetes (110). Patients with type 1 diabetes also had a higher proportion of echogenic and calcified plaques than subjects without type 1 diabetes (111). Furthermore, the frequency of carotid plaques was increased in patients with latent autoimmune diabetes in adults (LADA) compared to type 1 and type 2 diabetes, which was also increased with increasing diabetes duration in LADA (112). For diabetic complications, obesity, renal function decline, and diabetic retinopathy were investigated to be positively associated with the presence of carotid plaques (113-115). Therefore, carotid ultrasonography is necessary for the evaluation of vascular complications as well as the risk of cardiovascular events.

\section{Hypertension}

Hypertension is an important traditional risk factor, and antihypertensive targeted therapy is protective against cardiovascular events (116). Both high systolic and diastolic blood pressure at age 40 were demonstrated to be associated with carotid plaque burden late midlife (117). Additionally, carotid plaque score and CIMT were demonstrated to be potent predictors for stroke, and the former performed more accurately (118). H-type hypertension, characterized by hypertension and hyperhomocysteinemia with high cardio-cerebrovascular risk, was reported to be positively associated with higher presence of carotid plaques than isolated systolic hypertension and simple hypercysteinemia (119). Recently, Ben et al. also found that blood homocysteine levels in hypertensive patients with hyperhomocysteinemia were 
positively associated with carotid plaque thickness, stenosis degree, and contrast-enhanced ultrasound quantification, but negatively associated with shear wave velocity (120). Hence, carotid ultrasonography is a useful tool for atherosclerotic evaluation of hypertensive patients.

\section{Unhealthy Lifestyle}

An unhealthy lifestyle associated with increased cardiovascular risk can also promote carotid atherosclerosis. Smoking is one of the major atherosclerotic factors, and both current and former smokers were at higher risk of echodense carotid plaques than never smokers (121). Sedentary behavior is another common unhealthy lifestyle. A moderate level of physical activity with a sedentary time $\leq 3$ hours/day was associated with lower odds of the presence of carotid plaques, but no reduction in carotid plaque presence by physical activity combined with a sedentary time $>3$ hours/day (122). Moreover, a Western dietary pattern, including higher red meat, sugar intake, and deep-fried products, was positively associated with higher CIMT in the common carotid artery, which might contribute to future cardiovascular risk (123). Poor sleep quality and short sleep time, a universal phenomenon of menopause, were found to be associated with higher CIMT and odds of carotid plaques (124). Middle-aged male shift workers also had higher CIMT and carotid plaque presence than fixed daytime workers (125). Additionally, sleep apnea, defined as an apnea-hypopnea index of 15 events per hour, was associated with an increased presence of carotid plaque in subjects aged $<68$ years but not in older adults. Greater hypoxemia was also associated with increasing carotid intimamedia thickness in younger subjects but not in older adults (126). Patients with chronic obstructive pulmonary disease had higher CIMT (127), and lower pulmonary function was associated with an increased risk of carotid atherosclerosis compared to higher pulmonary function (128).

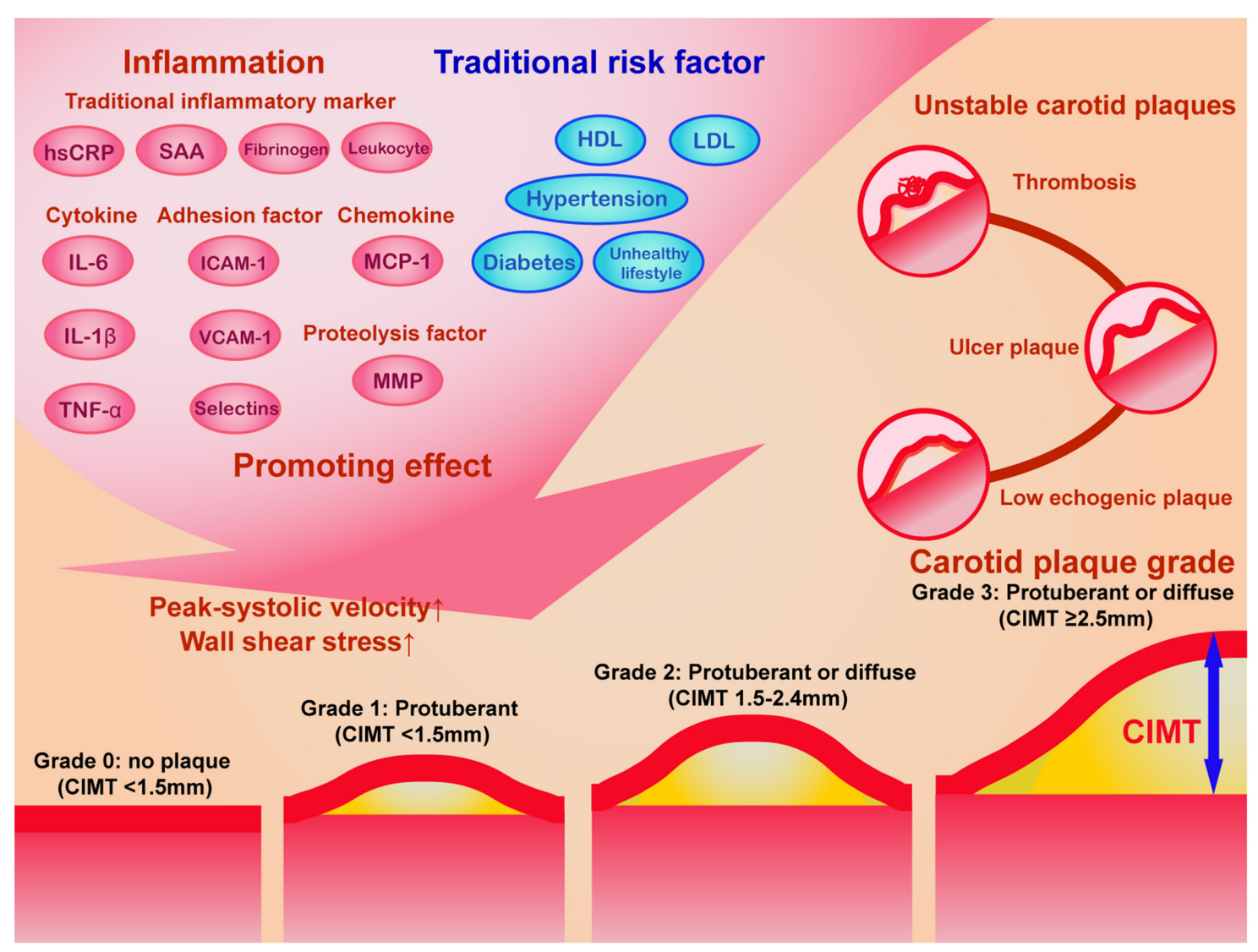

FIGURE 3 | The schematic diagram of the impact of inflammation and traditional risk factor on carotid plaque progression and the grading system of carotid plaques. Traditional inflammatory markers, cytokines, chemokines, adhesion factors, proteolysis factors, and other novel inflammatory factors, in combination with traditional risk factors promotes elevated carotid plaque grade and unstable carotid plaques. According to Recommendations for the Assessment of Carotid Arterial Plaque by Ultrasound from the American Society of Echocardiography in 2020 (41), the carotid plaque grade was classified into 4 levels: grade 0 (no plaques with CIMT $<1.5 \mathrm{~mm}$ ), grade 1 (protuberant CIMT $<1.5 \mathrm{~mm}$ ), grade 2 (protuberant or diffuse CIMT between 1.5 and $2.4 \mathrm{~mm}$ ), and grade 3 (protuberant or diffuse CIMT $\geq 2.5 \mathrm{~mm}$ ). The ultrasound characteristics of unstable carotid plaques includes low echogenic plaques, ulcer plaques, and thrombosis. CIMT, carotid intima-media thickness; HDL, high-density lipoprotein; hsCRP, hypersensitive C reactive protein; ICAM-1, intercellular cell adhesion molecule-1; IL-6, interleukin-6; IL-1 $\beta$, interleukin-1 beta; LDL, low-density lipoprotein; MCP, monocyte chemotactic protein-1; MMP, matrix metallopeptidase; TNF- $\alpha$, tumor necrosis factor-alpha; VCAM-1, vascular cell adhesion molecule-1. 


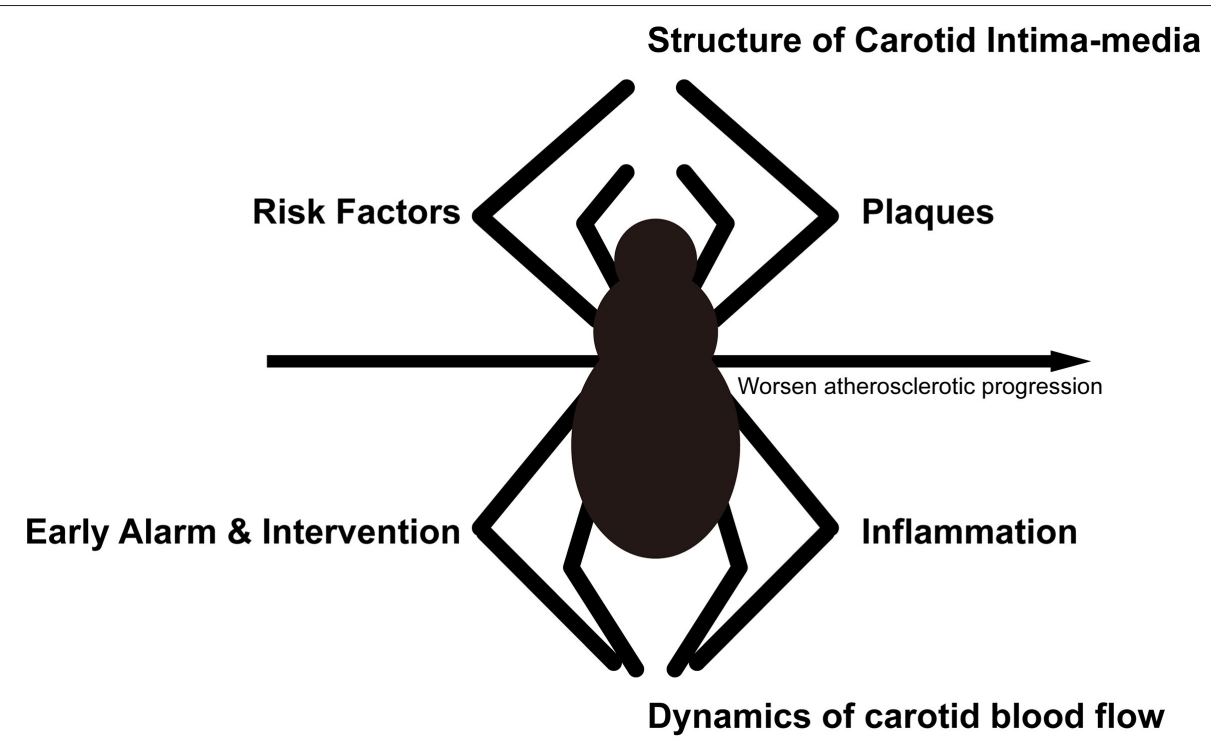

FIGURE 4 | Schematic diagram of the "SPIDER" proposal. The progression of atherosclerosis is similar to a spider spinning a web, and a full consideration of these 6 aspects may help to prevent the progression of atherosclerosis.

\section{Intervention for Traditional Risk Factors}

Traditional cardiovascular risk factors, including age, sex, blood pressure, smoking history, lipid levels, and diabetes, are independent determinants of the presence of carotid atherosclerosis (129-131). Previous evidence has shown that traditional risk factors do not largely contribute to the variance in CIMT and carotid plaque burden $(132,133)$. CVD risk factors have also been reported to partly account for of the total carotid plaque area and three-dimensional carotid plaque volume $(129,134)$. However, an improvement in CVD risk factors may not reduce carotid plaque progression to a greater extent than an early increase in the CIMT. As mentioned above, an early treat-to-target approach for CVD risk factors has been shown to slow down CIMT progression and reduce the risk of incident cardiovascular events in a high CIMT population without prior CVD (66). However, no benefits of exercise training in terms of CIMT reduction were observed in patients with established CVD (67). Moreover, in the Study of Women's Health Across the Nation, a healthier diet score was associated with a smaller CCA-IMT and CCA adventitial diameter, but it was not significantly correlated with the presence of carotid plaques (135). Our previous network meta-analysis also demonstrated that high-intensity statins and the combination therapy of statins and ezetimibe were associated with larger CIMT reduction compared to moderate/low-intensity statins and no statins, but the evidence for the association between statins and carotid plaque changes remained insufficient (136). Another populationbased observational study did not observe a correlation between omega-3 fatty acid consumption and the presence of carotid plaques (137).

Hence, CVD risk factors interact with carotid atherosclerosis, and treatments targeting CVD factors may possibly reverse carotid atherosclerosis in the early phase, but multidisciplinary efforts are needed for the early prevention of carotid atherosclerosis progression.

\section{EVALUATION OF CAROTID ULTRASONOGRAPHY COMBINED WITH CARDIOVASCULAR RISK FACTORS}

The prevalence of carotid atherosclerosis increases with age (39, 138); thus middle-aged and elderly individuals are at higher risk of carotid atherosclerosis and CVD than young adults and may benefit from carotid ultrasound detection. Inflammatory factors and traditional risk factors have integral effect on the hemodynamics and vessel dysfunction of carotid artery, which causes carotid plaque progression and instability (Figure 3). Additionally, high-risk plaque is not clearly defined, and lacks evidences for intervention, although it is largely correlated with cerebrovascular and cardiovascular disease. Several serum atherosclerotic biomarkers combined with carotid ultrasonography may assist clinicians in identifying high cardiovascular risk patients who need intervention (82). When evaluating the risk of CVD using carotid ultrasonography, the major problem is the lack of normative values of carotid ultrasound parameters and the weak combination of carotid ultrasound results with cardiovascular risk factors in clinical practice. Based on the comprehensive literature review and within the context of international guidelines $(1,33,34,139)$, we propose that atherosclerosis, like a web, is promoted and alarmed by the "SPIDER" (Figure 4), the name of which originated from the first letter of the 6 abovementioned aspects. A comprehensive assessment of combining carotid ultrasonography and other atherosclerotic factors may halt the progression of atherosclerosis for cardiovascular prevention. 


\section{CONCLUSION}

Carotid ultrasound results should be combined with other important atherosclerotic factors, and a comprehensive cardiovascular assessment can better predict CVD risk and guide primary preventative measures.

\section{AUTHOR CONTRIBUTIONS}

HL and XX contributed to literature review and manuscript drafting. BL contributed to providing image. YZ contributed to the conception of the work and assessed the quality of evidence

\section{REFERENCES}

1. Greenland P, Alpert JS, Beller GA, Benjamin EJ, Budoff MJ, Fayad ZA, et al. 2010 ACCF/AHA guideline for assessment of cardiovascular risk in asymptomatic adults: a report of the American college of cardiology foundation/American heart association task force on practice guidelines. $J$ Am Coll Cardiol. (2010) 56:e50-103. doi: 10.1016/j.jacc.2010.09.001

2. Liao X, Norata GD, Polak JF, Stehouwer CD, Catapano A, Rundek T, et al. Normative values for carotid intima media thickness and its progression: are they transferrable outside of their cohort of origin? Eur J Prev Cardiol. (2016) 23:1165-73. doi: 10.1177/2047487315625543

3. Den Ruijter HM, Peters SAE, Anderson TJ, Britton AR, Dekker JM, Eijkemans MJ, et al. Common carotid intima-media thickness measurements in cardiovascular risk prediction: a meta-analysis. JAMA. (2012) 308:796803. doi: 10.1001/jama.2012.9630

4. Stein JH, Korcarz CE, Hurst RT, Lonn E, Kendall CB, Mohler ER, et al. Use of carotid ultrasound to identify subclinical vascular disease and evaluate cardiovascular disease risk: a consensus statement from the American society of echocardiography carotid intima-media thickness task force. Endorsed by the society for vascular medicine. J Am Soc Echocardiogr. (2008) 21:93-111; quiz: 189-90. doi: 10.1016/j.echo.2007.11.011

5. Salonen JT, Salonen R. Ultrasonographically assessed carotid morphology and the risk of coronary heart disease. Arterioscler Thromb. (1991) 11:12459. doi: 10.1161/01.ATV.11.5.1245

6. Rundek T, Arif H, Boden-Albala B, Elkind MS, Paik MC, Sacco RL. Carotid plaque, a subclinical precursor of vascular events: the Northern Manhattan Study. Neurology. (2008) 70:1200-7. doi: 10.1212/01.wnl.0000303969.63165.34

7. Nezu T, Hosomi N. Usefulness of carotid ultrasonography for risk stratification of cerebral and cardiovascular disease. J Atheroscler Thromb. (2020) 27:1023-35. doi: 10.5551/jat.RV17044

8. Chambless LE, Heiss G, Folsom AR, Rosamond W, Szklo M, Sharrett $\mathrm{AR}$, et al. Association of coronary artery disease incidence with carotid arterial wall thickness and major risk factors: the atherosclerosis risk in communities (ARIC) study, 1987-1993. Atherosclerosis. (1997) 146:489-94. doi: 10.1093/oxfordjournals.aje.a009302

9. O'Leary DH, Polak JF, Kronmal RA, Manolio TA, Burke GL, Wolfson SK. Carotid-artery intima and media thickness as a risk factor for myocardial infarction and stroke in older adults. Cardiovascular Health Study Collaborative Research Group. N Engl J Med. (1999) 340:14-22. doi: 10.1056/NEJM199901073400103

10. Polak JF, Szklo M, Kronmal RA, Burke GL, Shea S, Zavodni AE, et al. The value of carotid artery plaque and intima-media thickness for incident cardiovascular disease: the multi-ethnic study of atherosclerosis. J Am Heart Assoc. (2013) 2:e000087. doi: 10.1161/JAHA.113.000087

11. Willeit P, Tschiderer L, Allara E, Reuber K, Seekircher L, Gao $\mathrm{L}$, et al. Carotid intima-media thickness progression as surrogate marker for cardiovascular risk: meta-analysis of 119 clinical trials involving 100667 patients. Circulation. (2020) 142:621-42. doi: 10.1161/CIRCULATIONAHA.120.046361 and suggestions. All authors contributed to the article and approved the submitted version.

\section{FUNDING}

This study was supported by the National Natural Science Foundation of China (NSFC) (Nos. 81970388 and 81801719), the Natural Science Foundation of Guangdong (No. 2019A1515011682), and the Development Funding of the International Science and Technology Innovation Center in the Greater Bay Area of the 2020-2022 Science and Technology Project of Guangdong Province (No. 2021A0505030021).

12. Rodriguez-Macias KA, Lind L, Naessen T. Thicker carotid intima layer and thinner media layer in subjects with cardiovascular diseases. An investigation using noninvasive high-frequency ultrasound. Atherosclerosis. (2006) 189:393-400. doi: 10.1016/j.atherosclerosis.2006.02.020

13. Lim TK, Lim E, Dwivedi G, Kooner J, Senior R. Normal value of carotid intima-media thickness-a surrogate marker of atherosclerosis: quantitative assessment by B-mode carotid ultrasound. J Am Soc Echocardiogr. (2008) 21:112-6. doi: 10.1016/j.echo.2007.05.002

14. Pastorius CA, Medina-Lezama J, Corrales-Medina F, Bernabe-Ortiz A, PazManrique R, Salinas-Najarro B, et al. Normative values and correlates of carotid artery intima-media thickness and carotid atherosclerosis in Andean-Hispanics: the Prevencion Study. Atherosclerosis. (2010) 211:499505. doi: 10.1016/j.atherosclerosis.2010.04.009

15. van der Meer IM, Bots ML, Hofman A, del Sol AI, van der Kuip DA, Witteman JC. Predictive value of noninvasive measures of atherosclerosis for incident myocardial infarction: the Rotterdam Study. Circulation. (2004) 109:1089-94. doi: 10.1161/01.CIR.0000120708.59 $903.1 \mathrm{~B}$

16. Rosvall M, Janzon L, Berglund G, Engström G, Hedblad B. Incident coronary events and case fatality in relation to common carotid intima-media thickness. J Intern Med. (2005) 257:430-7. doi: 10.1111/j.1365-2796.2005.01485.x

17. Lorenz MW, von Kegler S, Steinmetz H, Markus HS, Sitzer M. Carotid intima-media thickening indicates a higher vascular risk across a wide age range: prospective data from the Carotid Atherosclerosis Progression Study (CAPS). Stroke. (2006) 37:87-92. doi: 10.1161/01.STR.0000196964. 24024.ea

18. Price JF, Tzoulaki I, Lee AJ, Fowkes FG. Ankle brachial index and intima media thickness predict cardiovascular events similarly and increased prediction when combined. J Clin Epidemiol. (2007) 60:1067-75. doi: 10.1016/j.jclinepi.2007.01.011

19. Johnsen SH, Mathiesen EB, Joakimsen O, Stensland E, Wilsgaard T, Lochen ML, et al. Carotid atherosclerosis is a stronger predictor of myocardial infarction in women than in men: a 6-year follow-up study of 6226 persons: the Tromso Study. Stroke. (2007) 38:2873-80. doi: 10.1161/STROKEAHA.107.487264

20. Chien KL, Su TC, Jeng JS, Hsu HC, Chang WT, Chen MF, et al. Carotid artery intima-media thickness, carotid plaque and coronary heart disease and stroke in Chinese. PLoS ONE. (2008) 3:e3435. doi: 10.1371/journal.pone.0003435

21. Cournot M, Taraszkiewicz D, Cambou JP, Galinier M, Boccalon H, Hanaire-Broutin $\mathrm{H}$, et al. Additional prognostic value of physical examination, exercise testing, and arterial ultrasonography for coronary risk assessment in primary prevention. Am Heart J. (2009) 158:845-51. doi: 10.1016/j.ahj.2009.08.017

22. Plichart $M$, Celermajer DS, Zureik M, Helmer C, Jouven X, Ritchie $\mathrm{K}$, et al. Carotid intima-media thickness in plaque-free site, carotid plaques and coronary heart disease risk prediction in older adults. The Three-City Study. Atherosclerosis. (2011) 219:917-24. doi: 10.1016/j.atherosclerosis.2011.09.024 
23. Polak JF, Pencina MJ, Pencina KM, O'Donnell CJ, Wolf PA, D'Agostino RB Sr. Carotid-wall intima-media thickness and cardiovascular events. $N$ Engl J Med. (2011) 365:213-21. doi: 10.1056/NEJMoa1012592

24. Anderson TJ, Charbonneau F, Title LM, Buithieu J, Rose MS, Conradson $\mathrm{H}$, et al. Microvascular function predicts cardiovascular events in primary prevention: long-term results from the Firefighters and Their Endothelium (FATE) study. Circulation. (2011) 123:163-9. doi: 10.1161/CIRCULATIONAHA.110.953653

25. Baldassarre D, Hamsten A, Veglia F, de Faire U, Humphries SE, Smit AJ, et al. Measurements of carotid intima-media thickness and of interadventitia common carotid diameter improve prediction of cardiovascular events: results of the IMPROVE (Carotid Intima Media Thickness [IMT] and IMT-Progression as Predictors of Vascular Events in a High Risk European Population) study. J Am Coll Cardiol. (2012) 60:1489-99. doi: 10.1016/j.jacc.2012.06.034

26. Yeboah J, McClelland RL, Polonsky TS, Burke GL, Sibley CT, O’Leary D, et al. Comparison of novel risk markers for improvement in cardiovascular risk assessment in intermediate-risk individuals. JAMA. (2012) 308:788-95. doi: 10.1001/jama.2012.9624

27. Suzuki T, Wang W, Wilsdon A, Butler KR, Adabag S, Griswold ME, et al. Carotid intima-media thickness and the risk of sudden cardiac death: the ARIC study and the CHS. J Am Heart Assoc. (2020) 9:e016981. doi: 10.1161/JAHA.120.016981

28. Shimoda S, Kitamura A, Imano H, Cui R, Muraki I, Yamagishi K, et al. Associations of carotid intima-media thickness and plaque heterogeneity with the risks of stroke subtypes and coronary artery disease in the japanese general population: the circulatory risk in communities study. J Am Heart Assoc. (2020) 9:e017020. doi: 10.1161/JAHA.120.017020

29. Sillesen H, Sartori S, Sandholt B, Baber U, Mehran R, Fuster V. Carotid plaque thickness and carotid plaque burden predict future cardiovascular events in asymptomatic adult Americans. Eur Heart J Cardiovasc Imaging. (2018) 19:1042-50. doi: 10.1093/ehjci/jex239

30. Pignoli P, Tremoli E, Poli A, Oreste P, Paoletti R. Intimal plus medial thickness of the arterial wall: a direct measurement with ultrasound imaging. Circulation. (1986) 74:1399-406. doi: 10.1161/01.CIR.74.6.1399

31. Touboul PJ, Hennerici MG, Meairs S, Adams H, Amarenco P, Bornstein $\mathrm{N}$, et al. Mannheim carotid intima-media thickness and plaque consensus (2004-2006-2011). Cerebrovasc Dis. (2012) 34:290-6. doi: 10.1159/000343145

32. Lorenz MW, Polak JF, Kavousi M, Mathiesen EB, Völzke H, Tuomainen TP, et al. Carotid intima-media thickness progression to predict cardiovascular events in the general population (the PROG-IMT collaborative project): a meta-analysis of individual participant data. Lancet. (2012) 379:2053-62. doi: 10.1016/S0140-6736(12)60441-3

33. Piepoli MF, Hoes AW, Agewall S, Albus C, Brotons C, Catapano AL, et al. 2016 European guidelines on cardiovascular disease prevention in clinical practice: the sixth joint task force of the European society of cardiology and other societies on cardiovascular disease prevention in clinical practice (constituted by representatives of 10 societies and by invited experts) developed with the special contribution of the European association for cardiovascular prevention \& rehabilitation (EACPR). Eur Heart J. (2016) 37:2315-81. doi: 10.1093/eurheartj/ehw106

34. Cosentino F, Grant PJ, Aboyans V, Bailey CJ, Ceriello A, Delgado V, et al. 2019 ESC guidelines on diabetes, pre-diabetes, cardiovascular diseases developed in collaboration with the EASD. Eur Heart J. (2020) 41:255-323. doi: 10.1093/eurheartj/ehz486

35. Ridker PM, Hennekens CH, Buring JE, Rifai N. C-reactive protein and other markers of inflammation in the prediction of cardiovascular disease in women. $N$ Engl J Med. (2000) 342:836-43. doi: 10.1056/NEJM200003233421202

36. Bonithon-Kopp C, Touboul PJ, Berr C, Magne C, Ducimetiere P. Factors of carotid arterial enlargement in a population aged 59 to 71 years: the EVA study. Stroke. (1996) 27:654-60. doi: 10.1161/01.STR.27.4.654

37. Fritze F, Groß S, Ittermann T, Völzke H, Felix SB, Schminke U, et al. Carotid lumen diameter is associated with all-cause mortality in the general population. J Am Heart Assoc. (2020) 9:e015630. doi: 10.1161/JAHA.119.015630

38. Sedaghat S, van Sloten TT, Laurent S, London GM, Pannier B, Kavousi M, et al. Common carotid artery diameter and risk of cardiovascular events and mortality: pooled analyses of four cohort studies. Hypertension. (2018) 72:85-92. doi: 10.1161/HYPERTENSIONAHA.118.11253

39. Song P, Fang Z, Wang H, Cai Y, Rahimi K, Zhu Y, et al. Global and regional prevalence, burden, and risk factors for carotid atherosclerosis: a systematic review, meta-analysis, and modelling study. Lancet Glob Health. (2020) 8:e721-9. doi: 10.1016/S2214-109X(20)30117-0

40. Inaba Y, Chen JA, Bergmann SR. Carotid plaque, compared with carotid intima-media thickness, more accurately predicts coronary artery disease events: a meta-analysis. Atherosclerosis. (2012) 220:128-33. doi: 10.1016/j.atherosclerosis.2011.06.044

41. Johri AM, Nambi V, Naqvi TZ, Feinstein SB, Kim ESH, Park MM, et al. Recommendations for the assessment of carotid arterial plaque by ultrasound for the characterization of atherosclerosis and evaluation of cardiovascular risk: from the American society of echocardiography. J Am Soc Echocardiogr. (2020) 33:917-33. doi: 10.1016/j.echo.2020.04.021

42. Gregg S, Li TY, Hetu MF, Pang SC, Ewart P, Johri AM. Relationship between carotid artery atherosclerosis and bulb geometry. Int J Cardiovasc Imaging. (2018) 34:1081-90. doi: 10.1007/s10554-018-1319-z

43. Sirimarco G, Amarenco P, Labreuche J, Touboul PJ, Alberts M, Goto $\mathrm{S}$, et al. Carotid atherosclerosis and risk of subsequent coronary event in outpatients with atherothrombosis. Stroke. (2013) 44:373-9. doi: 10.1161/STROKEAHA.112.673129

44. Cao JJ, Arnold AM, Manolio TA, Polak JF, Psaty BM, Hirsch CH, et al. Association of carotid artery intima-media thickness, plaques, and creactive protein with future cardiovascular disease and all-cause mortality. Circulation. (2007) 116:32-8. doi: 10.1161/CIRCULATIONAHA.106.645606

45. Prabhakaran S, Singh R, Zhou X, Ramas R, Sacco RL, Rundek T. Presence of calcified carotid plaque predicts vascular events: the Northern Manhattan Study. Atherosclerosis. (2007) 195:e197-201. doi: 10.1016/j.atherosclerosis.2007.03.044

46. Gepner AD, Young R, Delaney JA, Budoff MJ, Polak JF, Blaha MJ, et al. Comparison of carotid plaque score and coronary artery calcium score for predicting cardiovascular disease events: the multiethnic study of atherosclerosis. J Am Heart Assoc. (2017) 6:e005179. doi: 10.1161/JAHA.116.005179

47. Mitchell C, Korcarz CE, Gepner AD, Kaufman JD, Post W, Tracy R, et al. Ultrasound carotid plaque features, cardiovascular disease risk factors and events: the Multi-Ethnic Study of Atherosclerosis. Atherosclerosis. (2018) 276:195-202. doi: 10.1016/j.atherosclerosis.2018.06.005

48. Handa N, Matsumoto M, Maeda H, Hougaku H, Ogawa S, Fukunaga R, et al. Ultrasonic evaluation of early carotid atherosclerosis. Stroke. (1990) 21:1567-72. doi: 10.1161/01.STR.21.11.1567

49. Prati P, Tosetto A, Casaroli M, Bignamini A, Canciani L, Bornstein $\mathrm{N}$, et al. Carotid plaque morphology improves stroke risk prediction: usefulness of a new ultrasonographic score. Cerebrovasc Dis. (2011) 31:3004. doi: 10.1159/000320852

50. Ikeda N, Kogame N, Iijima R, Nakamura M, Sugi K. Carotid artery intimamedia thickness and plaque score can predict the SYNTAX score. Eur Heart J. (2012) 33:113-9. doi: 10.1093/eurheartj/ehr399

51. Johri AM, Chitty DW, Matangi M, Malik P, Mousavi P, Day A, et al. Can carotid bulb plaque assessment rule out significant coronary artery disease? A comparison of plaque quantification by two- and three-dimensional ultrasound. J Am Soc Echocardiogr. (2013) 26:86-95. doi: 10.1016/j.echo.2012.09.005

52. Wannarong T, Parraga G, Buchanan D, Fenster A, House AA, Hackam DG, et al. Progression of carotid plaque volume predicts cardiovascular events. Stroke. (2013) 44:1859-65. doi: 10.1161/STROKEAHA.113. 001461

53. Mantella LE, Colledanchise KN, Hetu MF, Feinstein SB, Abunassar J, Johri AM. Carotid intraplaque neovascularization predicts coronary artery disease and cardiovascular events. Eur Heart J Cardiovasc Imaging. (2019) 20:123947. doi: 10.1093/ehjci/jez070

54. Toutouzas K, Drakopoulou M, Aggeli C, Nikolaou C, Felekos I, Grassos $\mathrm{H}$, et al. In vivo measurement of plaque neovascularisation and thermal heterogeneity in intermediate lesions of human carotid arteries. Heart. (2012) 98:1716-21. doi: 10.1136/heartjnl-2012-302507

55. Zamani M, Skagen K, Scott H, Lindberg B, Russell D, Skjelland M. Carotid plaque neovascularization detected with superb microvascular 
imaging ultrasound without using contrast media. Stroke. (2019) 50:3121-7. doi: 10.1161/STROKEAHA.119.025496

56. von Reutern GM, Goertler MW, Bornstein NM, Del Sette M, Evans DH, Hetzel A, et al. Grading carotid stenosis using ultrasonic methods. Stroke. (2012) 43:916-21. doi: 10.1161/STROKEAHA.111.636084

57. Chuang SY, Bai CH, Chen JR, Yeh WT, Chen HJ, Chiu HC, et al. Common carotid end-diastolic velocity and intima-media thickness jointly predict ischemic stroke in Taiwan. Stroke. (2011) 42:1338-44. doi: 10.1161/STROKEAHA.110.605477

58. Bellinazzi VR, Cipolli JA, Pimenta MV, Guimaraes PV, Pio-Magalhaes JA, Coelho-Filho OR, et al. Carotid flow velocity/diameter ratio is a predictor of cardiovascular events in hypertensive patients. J Hypertens. (2015) 33:205460. doi: 10.1097/HJH.0000000000000688

59. Tajik P, Meijer R, Duivenvoorden R, Peters SA, Kastelein JJ, Visseren FJ, et al. Asymmetrical distribution of atherosclerosis in the carotid artery: identical patterns across age, race, and gender. Eur J Prev Cardiol. (2012) 19:687-97. doi: $10.1177 / 1741826711410821$

60. Goudot G, Poree J, Pedreira O, Khider L, Julia P, Alsac JM, et al. Wall shear stress measurement by ultrafast vector flow imaging for atherosclerotic carotid stenosis. Ultraschall Med. (2021) 42:297-305. doi: 10.1055/a-1060-0529

61. Carallo C, Tripolino C, De Franceschi MS, Irace C, Xu XY, Gnasso A. Carotid endothelial shear stress reduction with aging is associated with plaque development in twelve years. Atherosclerosis. (2016) 251:63-9. doi: 10.1016/j.atherosclerosis.2016.05.048

62. Goudot G, Sitruk J, Jimenez A, Julia P, Khider L, Alsac JM, et al. Carotid plaque vulnerability assessed by combined shear wave elastography and ultrafast doppler compared to histology. Transl Stroke Res. (2021). doi: 10.1007/s12975-021-00920-6

63. Ren L, Wang L, You T, Liu Y, Wu F, Zhu L, et al. Perivascular adipose tissue modulates carotid plaque formation induced by disturbed flow in mice. $J$ Vasc Surg. (2019) 70:927-36 e4. doi: 10.1016/j.jvs.2018.09.064

64. Haberka M, Gasior Z. Carotid extra-media thickness in obesity and metabolic syndrome: a novel index of perivascular adipose tissue: extramedia thickness in obesity and metabolic syndrome. Atherosclerosis. (2015) 239:169-77. doi: 10.1016/j.atherosclerosis.2014.12.058

65. Näslund U, Ng N, Lundgren A, Fhärm E, Grönlund C, Johansson $\mathrm{H}$, et al. Visualization of asymptomatic atherosclerotic disease for optimum cardiovascular prevention (VIPVIZA): a pragmatic, open-label, randomised controlled trial. Lancet. (2019) 393:133-42. doi: 10.1016/S0140-6736(18)32818-6

66. Burggraaf B, van Breukelen-van der Stoep DF, de Vries MA, Klop B, Liem $\mathrm{AH}$, van de Geijn GM, et al. Effect of a treat-to-target intervention of cardiovascular risk factors on subclinical and clinical atherosclerosis in rheumatoid arthritis: a randomised clinical trial. Ann Rheum Dis. (2019) 78:335-41. doi: 10.1136/annrheumdis-2018-214075

67. Byrkjeland R, Stensaeth KH, Anderssen S, Njerve IU, Arnesen H, Seljeflot I, et al. Effects of exercise training on carotid intima-media thickness in patients with type 2 diabetes and coronary artery disease. Influence of carotid plaques. Cardiovasc Diabetol. (2016) 15:13. doi: 10.1186/s12933-016-0336-2

68. Janjua SA, Staziaki PV, Szilveszter B, Takx RAP, Mayrhofer T, Hennessy O, et al. Presence, characteristics, and prognostic associations of carotid plaque among People living with HIV. Circ Cardiovasc Imaging. (2017) 10:e005777. doi: 10.1161/CIRCIMAGING.116.005777

69. Jud P, Kessler HH, Brodmann M. Case report: changes of vascular reactivity and arterial stiffness in a patient with Covid-19 infection. Front Cardiovasc Med. (2021) 8:671669. doi: 10.3389/fcvm.2021.671669

70. Wu GC, Liu HR, Leng RX, Li XP, Li XM, Pan HF, et al. Subclinical atherosclerosis in patients with systemic lupus erythematosus: a systemic review and meta-analysis. Autoimmun Rev. (2016) 15:22-37. doi: 10.1016/j.autrev.2015.10.002

71. Kiechl S, Egger G, Mayr M, Wiedermann CJ, Bonora E, Oberhollenzer F, et al. Chronic infections and the risk of carotid atherosclerosis: prospective results from a large population study. Circulation. (2001) 103:1064-70. doi: 10.1161/01.CIR.103.8.1064

72. Gonzalez-Gay MA, Gonzalez-Juanatey C, Vazquez-Rodriguez TR, Martin J, Llorca J. Endothelial dysfunction, carotid intima-media thickness, and accelerated atherosclerosis in rheumatoid arthritis.
Semin Arthritis Rheum. (2008) 38:67-70. doi: 10.1016/j.semarthrit.2008. 02.001

73. Gonzalez-Juanatey C, Llorca J, Martin J, Gonzalez-Gay MA. Carotid intimamedia thickness predicts the development of cardiovascular events in patients with rheumatoid arthritis. Semin Arthritis Rheum. (2009) 38:366-71. doi: 10.1016/j.semarthrit.2008.01.012

74. Corrales A, Vegas-Revenga N, Rueda-Gotor J, Portilla V, Atienza-Mateo B, Blanco R, et al. Carotid plaques as predictors of cardiovascular events in patients with Rheumatoid Arthritis. Results from a 5-yearprospective follow-up study. Semin Arthritis Rheum. (2020) 50:1333-8. doi: 10.1016/j.semarthrit.2020.03.011

75. Corrales A, Gonzalez-Juanatey C, Peiro ME, Blanco R, Llorca J, Gonzalez-Gay MA. Carotid ultrasound is useful for the cardiovascular risk stratification of patients with rheumatoid arthritis: results of a population-based study. Ann Rheum Dis. (2014) 73:722-7. doi: 10.1136/annrheumdis-2012-203101

76. Corrales A, Parra JA, Gonzalez-Juanatey C, Rueda-Gotor J, Blanco R, Llorca $\mathrm{J}$, et al. Cardiovascular risk stratification in rheumatic diseases: carotid ultrasound is more sensitive than Coronary Artery Calcification Score to detect subclinical atherosclerosis in patients with rheumatoid arthritis. Ann Rheum Dis. (2013) 72:1764-70. doi: 10.1136/annrheumdis-2013-203688

77. SahBandar IN, Ndhlovu LC, Saiki K, Kohorn LB, Peterson MM, D'Antoni $\mathrm{ML}$, et al. Relationship between circulating inflammatory monocytes and cardiovascular disease measures of carotid intimal thickness. J Atheroscler Thromb. (2020) 27:441-8. doi: 10.5551/jat.49791

78. Pettersson-Pablo P, Cao Y, Breimer LH, Nilsson TK, Hurtig-Wennlof A. Pulse wave velocity, augmentation index, and carotid intima-media thickness are each associated with different inflammatory protein signatures in young healthy adults: the lifestyle, biomarkers and atherosclerosis study. Atherosclerosis. (2020) 313:150-5. doi: 10.1016/j.atherosclerosis.2020.09.027

79. Ridker PM, Everett BM, Thuren T, MacFadyen JG, Chang WH, Ballantyne C, et al. Antiinflammatory therapy with canakinumab for atherosclerotic disease. N Engl J Med. (2017) 377:1119-31. doi: 10.1056/NEJMoa1707914

80. Schillinger M, Exner M, Mlekusch W, Sabeti S, Amighi J, Nikowitsch R, et al. Inflammation and carotid artery-risk for atherosclerosis study (ICARAS). Circulation. (2005) 111:2203-9. doi: 10.1161/01.CIR.0000163569.97918.C0

81. Willeit P, Thompson SG, Agewall S, Bergstrom G, Bickel H, Catapano AL, et al. Inflammatory markers and extent and progression of early atherosclerosis: meta-analysis of individual-participant-data from 20 prospective studies of the PROG-IMT collaboration. Eur J Prev Cardiol. (2016) 23:194-205. doi: $10.1177 / 2047487314560664$

82. Martinez E, Martorell J, Riambau V. Review of serum biomarkers in carotid atherosclerosis. J Vasc Surg. (2020) 71:329-41. doi: 10.1016/j.jvs.2019. 04.488

83. Guaricci AI, Pontone G, Fusini L, De Luca M, Cafarelli FP, Guglielmo M, et al. Additional value of inflammatory biomarkers and carotid artery disease in prediction of significant coronary artery disease as assessed by coronary computed tomography angiography. Eur Heart J Cardiovasc Imaging. (2017) 18:1049-56. doi: 10.1093/ehjci/jew173

84. Sugioka K, Naruko T, Hozumi T, Nakagawa M, Kitabayashi C, Ikura Y, et al. Elevated levels of neopterin are associated with carotid plaques with complex morphology in patients with stable angina pectoris. Atherosclerosis. (2010) 208:524-30. doi: 10.1016/j.atherosclerosis.2009.07.054

85. Firoz CK, Jabir NR, Kamal MA, Alama MN, Damanhouri GA, Khan W, et al. Neopterin: An immune biomarker of coronary artery disease and its association with other CAD markers. IUBMB Life. (2015) 67:453-9. doi: 10.1002/iub.1390

86. Bueno A, March JR, Garcia P, Canibano C, Ferruelo A, Fernandez-Casado JL. Carotid plaque inflammation assessed by (18)F-FDG PET/CT and Lp-PLA2 is higher in symptomatic patients. Angiology. (2021) 72:260-7. doi: 10.1177/0003319720965419

87. Khuseyinova N, Imhof A, Rothenbacher D, Trischler G, Kuelb S, Scharnagl $\mathrm{H}$, et al. Association between Lp-PLA2 and coronary artery disease: focus on its relationship with lipoproteins and markers of inflammation and hemostasis. Atherosclerosis. (2005) 182:181-8. doi: 10.1016/j.atherosclerosis.2004.10.046

88. Holm S, Ueland T, Dahl TB, Michelsen AE, Skjelland M, Russell D, et al. Fatty acid binding protein 4 is associated with carotid atherosclerosis and 
outcome in patients with acute ischemic stroke. PLoS ONE. (2011) 6:e28785. doi: 10.1371/journal.pone.0028785

89. Egbuche O, Biggs ML, Ix JH, Kizer JR, Lyles MF, Siscovick DS, et al. Fatty acid binding protein-4 and risk of cardiovascular disease: the cardiovascular health study. J Am Heart Assoc. (2020) 9:e014070. doi: 10.1161/JAHA.119.014070

90. Ghorbani A, Bhambhani V, Christenson RH, Meijers WC, de Boer RA, Levy D, et al. Longitudinal change in galectin-3 and incident cardiovascular outcomes. J Am Coll Cardiol. (2018) 72:3246-54. doi: 10.1016/j.jacc.2018.09.076

91. Kadoglou NP, Sfyroeras GS, Spathis A, Gkekas C, Gastounioti A, Mantas G, et al. Galectin-3, carotid plaque vulnerability, and potential effects of statin therapy. Eur J Vasc Endovasc Surg. (2015) 49:4-9. doi: 10.1016/j.ejvs.2014.10.009

92. Si W, He P, Wang Y, Fu Y, Li X, Lin X, et al. Complement complex C5b-9 levels are associated with the clinical outcomes of acute ischemic stroke and carotid plaque stability. Transl Stroke Res. (2019) 10:279-86. doi: 10.1007/s12975-018-0658-3

93. Maksimowicz-McKinnon K, Magder LS, Petri M. Predictors of carotid atherosclerosis in systemic lupus erythematosus. I Rheumatol. (2006) 33:2458-63.

94. Reynolds HR, Buyon J, Kim M, Rivera TL, Izmirly P, Tunick P, et al. Association of plasma soluble E-selectin and adiponectin with carotid plaque in patients with systemic lupus erythematosus. Atherosclerosis. (2010) 210:569-74. doi: 10.1016/j.atherosclerosis.2009.12.007

95. Ammirati E, Moroni F, Norata GD, Magnoni M, Camici PG. Markers of inflammation associated with plaque progression and instability in patients with carotid atherosclerosis. Mediators Inflamm. (2015) 2015:718329. doi: 10.1155/2015/718329

96. Nakagomi A, Shibui T, Kohashi K, Kosugi M, Kusama Y, Atarashi $\mathrm{H}$, et al. Differential effects of atorvastatin and pitavastatin on inflammation, insulin resistance, and the carotid intima-media thickness in patients with dyslipidemia. J Atheroscler Thromb. (2015) 22:1158-71. doi: $10.5551 /$ jat. 29520

97. Bian L, Xia L, Wang Y, Jiang J, Zhang Y, Li D, et al. Risk factors of subclinical atherosclerosis and plaque burden in high risk individuals: results from a community-based study. Front Physiol. (2018) 9:739. doi: 10.3389/fphys.2018.00739

98. Johnsen SH, Mathiesen EB, Fosse E, Joakimsen O, Stensland-Bugge E, Njolstad I, et al. Elevated high-density lipoprotein cholesterol levels are protective against plaque progression: a follow-up study of 1952 persons with carotid atherosclerosis the Tromso study. Circulation. (2005) 112:498-504. doi: 10.1161/CIRCULATIONAHA.104.522706

99. El Khoudary SR, Ceponiene I, Samargandy S, Stein JH, Li D, Tattersall $\mathrm{MC}$, et al. HDL (high-density lipoprotein) metrics and atherosclerotic risk in women. Arteriosclerosis Thromb Vasc Biol. (2018) 38:2236-44. doi: 10.1161/ATVBAHA.118.311017

100. Tiozzo E, Gardener H, Hudson BI, Dong C, Della-Morte D, Crisby $\mathrm{M}$, et al. High-density lipoprotein subfractions and carotid plaque: the Northern Manhattan Study. Atherosclerosis. (2014) 237:163-8. doi: 10.1016/j.atherosclerosis.2014.09.002

101. Aroner SA, Koch M, Mukamal KJ, Furtado JD, Stein JH, Tattersall MC, et al. High-density lipoprotein subspecies defined by apolipoprotein C-III and subclinical atherosclerosis measures: MESA (the multiethnic study of atherosclerosis). J Am Heart Assoc. (2018) 7:e007824. doi: 10.1161/JAHA.117.007824

102. Shea S, Stein JH, Jorgensen NW, McClelland RL, Tascau L, Shrager S, et al. Cholesterol mass efflux capacity, incident cardiovascular disease, and progression of carotid plaque. Arteriosclerosis Thromb Vasc Biol. (2019) 39:89-96. doi: 10.1161/ATVBAHA.118.311366

103. Ma H, Lin H, Hu Y, Li X, He W, Jin X, et al. Relationship between non-highdensity lipoprotein cholesterol and carotid atherosclerosis in normotensive and euglycemic Chinese middle-aged and elderly adults. Lipids Health Dis. (2017) 16:55. doi: 10.1186/s12944-017-0451-4

104. Liu Y, Zhang Z, Xia B, Wang L, Zhang H, Zhu Y, et al. Relationship between the non-HDLc-to-HDLc ratio and carotid plaques in a high stroke risk population: a cross-sectional study in China. Lipids Health Dis. (2020) 19:168. doi: 10.1186/s12944-020-01344-1
105. Mach F, Baigent C, Catapano AL, Koskinas KC, Casula M, Badimon L, et al. 2019 ESC/EAS guidelines for the management of dyslipidaemias: lipid modification to reduce cardiovascular risk. Eur Heart J. (2020) 41:111-88. doi: 10.15829/1560-4071-2020-3826

106. Matthews KA, El Khoudary SR, Brooks MM, Derby CA, Harlow SD, BarinasMitchell EJ, et al. Lipid changes around the final menstrual period predict carotid subclinical disease in postmenopausal women. Stroke. (2017) 48:706. doi: 10.1161/STROKEAHA.116.014743

107. Gao S, Zhao D, Qi Y, Wang W, Wang M, Sun J, et al. Circulating oxidized low-density lipoprotein levels independently predict 10 -year progression of subclinical carotid atherosclerosis: a community-based cohort study. $J$ Atheroscler Thromb. (2018) 25:1032-43. doi: 10.5551/jat.43299

108. Amarenco P, Hobeanu C, Labreuche J, Charles H, Giroud M, Meseguer E, et al. Carotid atherosclerosis evolution when targeting a lowdensity lipoprotein cholesterol concentration $<70 \mathrm{mg} / \mathrm{dL}$ after an ischemic stroke of atherosclerotic origin. Circulation. (2020) 142:748-57. doi: 10.1161/CIRCULATIONAHA.120.046774

109. Cosentino F, Grant PJ, Aboyans V, Bailey CJ, Ceriello A, Delgado V, et al. 2019 ESC Guidelines on diabetes, pre-diabetes, cardiovascular diseases developed in collaboration with the EASD. Eur Heart J. (2020) 41:255-323.

110. Vigili de Kreutzenberg S, Fadini GP, Guzzinati S, Mazzucato M, Volpi A, Coracina A, et al. Carotid plaque calcification predicts future cardiovascular events in type 2 diabetes. Diabetes Care. (2015) 38:1937-44. doi: $10.2337 / \mathrm{dc} 15-0327$

111. Castelblanco E, Betriu A, Hernandez M, Granado-Casas M, Ortega E, Soldevila B, et al. Ultrasound tissue characterization of carotid plaques differs between patients with type 1 diabetes and subjects without diabetes. J Clin Med. (2019) 8:424. doi: 10.3390/jcm8040424

112. Hernandez M, Lopez C, Real J, Valls J, Ortega-Martinez de Victoria E, Vazquez F, et al. Preclinical carotid atherosclerosis in patients with latent autoimmune diabetes in adults (LADA), type 2 diabetes and classical type 1 diabetes. Cardiovasc Diabetol. (2017) 16:94. doi: 10.1186/s12933-017-0576-9

113. Botvin Moshe C, Haratz S, Ravona-Springer R, Heymann A, Hung-Mo L, Schnaider Beeri M, et al. Long-term trajectories of BMI predict carotid stiffness and plaque volume in type 2 diabetes older adults: a cohort study. Cardiovasc Diabetol. (2020) 19:138. doi: 10.1186/s12933-020-01104-6

114. Seo DH, Kim SH, Song JH, Hong S, Suh YJ, Ahn SH, et al. Presence of carotid plaque is associated with rapid renal function decline in patients with type 2 diabetes mellitus and normal renal function. Diabetes Metab J. (2019) 43:840-53. doi: 10.4093/dmj.2018.0186

115. Alonso N, Traveset A, Rubinat E, Ortega E, Alcubierre N, Sanahuja J, et al. Type 2 diabetes-associated carotid plaque burden is increased in patients with retinopathy compared to those without retinopathy. Cardiovasc Diabetol. (2015) 14:33. doi: 10.1186/s12933-015-0196-1

116. Whelton PK, Carey RM, Aronow WS, Casey DE Jr, Collins KJ, Dennison Himmelfarb C, et al. 2017 ACC/AHA/AAPA/ABC/ACPM/AGS/APhA/ASH/ASPC/NMA/PCNA guideline for the prevention, detection, evaluation, and management of high blood pressure in adults: executive summary: a report of the American College of Cardiology/American Heart Association Task Force on Clinical Practice Guidelines. Hypertension. (2018) 71:1269-324. doi: 10.1161/HYP.0000000000000065

117. Vigen T, Ihle-Hansen H, Lyngbakken MN, Berge T, Thommessen B, IhleHansen $\mathrm{H}$, et al. Blood pressure at age 40 predicts carotid atherosclerosis two decades later: data from the Akershus Cardiac Examination 1950 Study. J Hypertens. (2019) 37:1982-90. doi: 10.1097/HJH.0000000000 002131

118. Kawai T, Ohishi M, Takeya $\mathrm{Y}$, Onishi $\mathrm{M}$, Ito $\mathrm{N}$, Oguro $\mathrm{R}$, et al. Carotid plaque score and intima media thickness as predictors of stroke and mortality in hypertensive patients. Hypertens Res. (2013) 36:902-9. doi: $10.1038 / \mathrm{hr} .2013 .61$

119. Chen Z, Wang F, Zheng Y, Zeng Q, Liu H. H-type hypertension is an important risk factor of carotid atherosclerotic plaques. Clin Exp Hypertens. (2016) 38:424-8. doi: 10.3109/10641963.2015.1116547

120. Ben Z, Wang J, Zhan J, Li X, Ruan H, Chen S. Characteristics of the carotid plaque in hypertensive patients with hyperhomocysteinemia using multimode ultrasound. J Stroke Cerebrovasc Dis. (2020) 29:104925. doi: 10.1016/j.jstrokecerebrovasdis.2020.104925 
121. Yang D, Iyer S, Gardener H, Della-Morte D, Crisby M, Dong C, et al. Cigarette smoking and carotid plaque echodensity in the Northern Manhattan study. Cerebrovasc Dis. (2015) 40:136-43. doi: 10.1159/000434761

122. Walker TJ, Heredia NI, Lee M, Laing ST, Fisher-Hoch SP, McCormick JB, et al. The combined effect of physical activity and sedentary behavior on subclinical atherosclerosis: a cross-sectional study among Mexican Americans. BMC Public Health. (2019) 19:161. doi: 10.1186/s12889-019-6439-4

123. Wang D, Karvonen-Gutierrez CA, Jackson EA, Elliott MR, Appelhans $\mathrm{BM}$, Barinas-Mitchell E, et al. Western dietary pattern derived by multiple statistical methods is prospectively associated with subclinical carotid atherosclerosis in midlife women. J Nutr. (2020) 150:579-91. doi: $10.1093 / \mathrm{jn} / \mathrm{nxz} 270$

124. Thurston RC, Chang Y, von Kanel R, Barinas-Mitchell E, Jennings JR, Hall $\mathrm{MH}$, et al. Sleep characteristics and carotid atherosclerosis among midlife women. Sleep. (2017) 40:zsw052. doi: 10.1093/sleep/zsw052

125. Sugiura T, Dohi Y, Takagi Y, Yoshikane N, Ito M, Suzuki K, et al. Impacts of lifestyle behavior and shift work on visceral fat accumulation and the presence of atherosclerosis in middle-aged male workers. Hypertens Res. (2020) 43:235-45. doi: 10.1038/s41440-019-0362-Z

126. Zhao YY, Javaheri S, Wang R, Guo N, Koo BB, Stein JH, et al. Associations between sleep apnea and subclinical carotid atherosclerosis: the multi-ethnic study of atherosclerosis. Stroke. (2019) 50:3340-6. doi: 10.1161/STROKEAHA.118.022184

127. Wang LY, Zhu YN, Cui JJ, Yin KQ, Liu SX, Gao YH. Subclinical atherosclerosis risk markers in patients with chronic obstructive pulmonary disease: a systematic review and meta-analysis. Respir Med. (2017) 123:1827. doi: 10.1016/j.rmed.2016.12.004

128. Pan J, Xu L, Cai SX, Jiang CQ, Cheng KK, Zhao HJ, et al. The association of pulmonary function with carotid atherosclerosis in older Chinese: Guangzhou Biobank Cohort Study-CVD Subcohort. Atherosclerosis. (2015) 243:469-76. doi: 10.1016/j.atherosclerosis.2015.09.036

129. Spence JD, Barnett PA, Bulman DE, Hegele RA. An approach to ascertain probands with a non-traditional risk factor for carotid atherosclerosis. Atherosclerosis. (1999) 144:429-34. doi: 10.1016/S0021-9150(99) 00003-9

130. Salonen R, Seppänen K, Rauramaa R, Salonen JT. Prevalence of carotid atherosclerosis and serum cholesterol levels in eastern Finland. Arteriosclerosis. (1988) 8:788-92. doi: 10.1161/01.ATV. 8.6.788

131. Mannami T, Konishi M, Baba S, Nishi N, Terao A. Prevalence of asymptomatic carotid atherosclerotic lesions detected by high-resolution ultrasonography and its relation to cardiovascular risk factors in the general population of a Japanese city: the Suita study. Stroke. (1997) 28:518-25. doi: 10.1161/01.STR.28.3.518

132. Rundek T, Blanton SH, Bartels S, Dong C, Raval A, Demmer RT, et al. Traditional risk factors are not major contributors to the variance in carotid intima-media thickness. Stroke. (2013) 44:2101-8. doi: 10.1161/STROKEAHA.111.000745
133. Kuo F, Gardener H, Dong C, Cabral D, Della-Morte D, Blanton SH, et al. Traditional cardiovascular risk factors explain the minority of the variability in carotid plaque. Stroke. (2012) 43:1755-60. doi: 10.1161/STROKEAHA.112.651059

134. Noflatscher M, Schreinlechner M, Sommer P, Kerschbaum J, Berggren K, Theurl M, et al. Influence of traditional cardiovascular risk factors on carotid and femoral atherosclerotic plaque volume as measured by threedimensional ultrasound. J Clin Med. (2018) 8:32. doi: 10.3390/jcm8010032

135. Wang D, Jackson EA, Karvonen-Gutierrez CA, Elliott MR, Harlow SD, Hood $\mathrm{MM}$, et al. Healthy lifestyle during the midlife is prospectively associated with less subclinical carotid atherosclerosis: the study of women's health across the nation. J Am Heart Assoc. (2018) 7:e010405. doi: 10.1161/JAHA.118.010405

136. Li H, Xu X, Lu L, Sun R, Guo Q, Chen Q, et al. The comparative impact among different intensive statins and combination therapies with niacin/ezetimibe on carotid intima-media thickness: a systematic review, traditional meta-analysis, and network meta-analysis of randomized controlled trials. Eur J Clin Pharmacol. (2021) 77:1133-45. doi: 10.1007/s00228-021-03113-0

137. Ebbesson SO, Roman MJ, Devereux RB, Kaufman D, Fabsitz RR, Maccluer JW, et al. Consumption of omega-3 fatty acids is not associated with a reduction in carotid atherosclerosis: the Genetics of Coronary Artery Disease in Alaska Natives study. Atherosclerosis. (2008) 199:346-53. doi: 10.1016/j.atherosclerosis.2007.10.020

138. Joakimsen O, Bonaa KH, Stensland-Bugge E, Jacobsen BK. Age and sex differences in the distribution and ultrasound morphology of carotid atherosclerosis: the Tromsø Study. Arteriosclerosis Thromb Vasc Biol. (1999) 19:3007-13. doi: 10.1161/01.ATV.19.12.3007

139. Goff DC Jr, Lloyd-Jones DM, Bennett G, Coady S, D’Agostino RB, Gibbons $\mathrm{R}$, et al. 2013 ACC/AHA guideline on the assessment of cardiovascular risk: a report of the American college of cardiology/American heart association task force on practice guidelines. Circulation. (2014) 129:S49-73. doi: 10.1161/01.cir.0000437741.48606.98

Conflict of Interest: The authors declare that the research was conducted in the absence of any commercial or financial relationships that could be construed as a potential conflict of interest.

Publisher's Note: All claims expressed in this article are solely those of the authors and do not necessarily represent those of their affiliated organizations, or those of the publisher, the editors and the reviewers. Any product that may be evaluated in this article, or claim that may be made by its manufacturer, is not guaranteed or endorsed by the publisher.

Copyright (c) $2021 \mathrm{Li}, \mathrm{Xu}, \mathrm{Luo}$ and Zhang. This is an open-access article distributed under the terms of the Creative Commons Attribution License (CC BY). The use, distribution or reproduction in other forums is permitted, provided the original author(s) and the copyright owner(s) are credited and that the original publication in this journal is cited, in accordance with accepted academic practice. No use, distribution or reproduction is permitted which does not comply with these terms. 